NASA Technical Memorandum 102137

AIAA-89-3520

\title{
Integrated Flight/Propulsion Control System Design Based on a Centralized Approach
}

\author{
(NA SA-TM-102137) INTEGBATED \\ FLIGHT/PROPULSION CONTHOL SYSTEM DESIGN \\ BASED ON A CENTEALIZED APPROACH (NASA. \\ Lewis Research (enter) $41 \mathrm{p}$ CSCL O1C \\ N 89-26009 \\ Unclas \\ G3/08 0219608
}

Sanjay Garg and Duane L. Mattern

Sverdrup Technology, Inc.

NASA Lewis Research Center Group

Cleveland, Ohio

and

Randy E. Bullard

National Aeronautics and Space Administration

Lewis Research Center

Cleveland, Ohio

Prepared for the

Guidance, Navigation and Control Conference

sponsored by the American Institute of Aeronautics and Astronautics

Boston, Massachusetts, August 14-16, 1989

\section{N/SN}




\title{
INTEGRATED FLIGHT/PROPULSION CONTROL SYSTEM DESIGN BASED ON A CENTRALIZED APPROACH
}

\author{
Sanjay Garg ${ }^{1}$ and Duane L. Mattern ${ }^{2}$ \\ Sverdrup Technology, Inc. \\ NASA Lewis Research Center Group \\ Cleveland, Ohio 44135 \\ and \\ Randy E. Bullard ${ }^{3}$ \\ National Aeronautics and Space Administration \\ Lewis Research Center \\ Cleveland, Ohio 44135
}

\begin{abstract}
In this paper, an integrated flight/propulsion control system design is presented for the piloted longitudinal landing task with a modern, statically unstable, fighter aircraft. A centralized compensator based on the Linear Quadratic Gaussian/Loop Transfer Recovery methodology is first obtained to satisfy the feedback loop performance and robustness specifications. This high-order centralized compensator is then partitioned into airframe and engine "sub-controllers" based on modal controllability/observability for the compensator modes. The order of the sub-controllers is then reduced using internally-balanced realization techniques and the sub-controllers are simplified by neglecting the insignificant feedbacks. These sub-controllers have the advantage that they can be implemented as separate controllers on the airframe and the engine while still retaining the important performance and stability characteristics of the full-order centralized compensator. Command prefilters are then designed for the closed-loop system with the simplified sub-controllers to obtain the desired system response to airframe and engine command inputs, and the overall system performance evaluation results are

\footnotetext{
${ }^{1}$ Controls Engineer, Member AIAA

${ }^{2}$ Controls Engineer

${ }^{3}$ Aerospace Control Systems Engineer, currently with M.K. Ferguson Co., Cleveland, Ohio.
} 
presented.

\section{Introduction}

The desire to enlarge the flight envelope of tactical aircraft and provide new/enhanced maneuver capabilities has led to the use of forces and moments produced by the propulsion system to augment the flight control function. The coupling between the propulsion system dynamics and the airframe dynamics, which results from such an application of the propulsion system forces and moments, is significant enough that the traditional approach of designing the propulsion control system and the flight control system separately and then putting them together in an ad-hoc manner is no longer adequate. An integrated approach to flight/propulsion control system design is then required in order to obtain an overall system that will ensure optimum performance with minimal pilot workload.

In the early 1980s, the Air Force initiated a study called the Design Methods for Integrated Control Systems (DMICS) with the objective of developing methodologies for the design of Integrated Flight/Propulsion Control (IFPC) laws for an advanced tactical aircraft. Two very different approaches to IFPC design came about as a result of this study. These are :

(i) A Linear Quadratic Gaussian - Loop Transfer Recovery (LQG/LTR) based centralized approach which consists of designing a "global" integrated compensator considering the fully integrated system as one high-order system ${ }^{[1]}$.

(ii) A decentralized, hierarchical approach which consists of partitioning the integrated system into loosely coupled sub-systems and then designing separate controllers for the sub-systems, using Linear Quadratic Regulator (LQR) based explicit model-following type of approach, such that some high-level performance criterion are met ${ }^{[2]}$.

More recently, a joint NASA Lewis and NASA Ames research program, called the Short 
Take-Off and Vertical Landing (STOVL) Integrated Flight/Propulsion Controls program $^{[3]}$, has been initiated with the objective of developing the enabling technologies that will lead to a demonstrator aircraft with Supersonic STOVL capability in the 1990s. One of the elements of this program is to develop IFPC design methodologies that will provide a viable alternative to the methodologies developed under the DMICS study while allowing for improved system performance and simplicity of control law synthesis and implementation. Before embarking on developing an alternative to DMICS, it is meaningful to conduct an extensive review of the two DMICS methodologies and develop a thorough understanding of the control law synthesis and evaluation procedures by way of an example study. Towards this goal, results are reported in this paper from an example application of the LQG/LTR-based DMICS approach to IFPC design for the piloted longitudinal landing task with a modern, statically unstable fighter aircraft. This study, however, takes the IFPC design process a step beyond that reported in Ref. [1], in that the high-order centralized compensator is partitioned into simplified lower-order sub-controllers which can be implemented separately on the airframe and the engine without any significant loss of overall system performance and robustness.

In the following, the LQG/LTR-based DMICS control law design procedure is first briefly summarized. The vehicle model is then discussed, and the design specifications are stated. The centralized feedback compensator design is then presented and the closed-loop performance and robustness characteristics are discussed. The procedure for partitioning the centralized compensator into separate airframe and engine sub-controllers is discussed next and closed-loop evaluation results are presented for the system consisting of the simplified sub-controllers. Finally, prefilter design results are presented to provide command shaping such that the closed-loop system response to airframe and engine command inputs is as desired. 


\section{Control Law Design Methodology}

The salient features of the LQG/LTR-based DMICS methodology are briefly discussed in the following. This discussion is based on the description of the methodology in Ref. [4].

The nonlinear simulation of the complete aircraft system is first used to obtain linear models at various design points along the aircraft flight envelope. An open-loop analysis of the plant, at each design point, is performed to assess the number of degrees of freedom and to define the candidate variables to be regulated and/or commanded. To determine the plant degrees of freedom, an input/output scaling (normalization) of the plant is performed. This scaling consists of normalizing the plant inputs by the maximum allowable deflection of the control effector and normalizing the plant outputs by the maximum value to be commanded or the maximum allowable deviation from trim. The singular values of the scaled plant transfer matrix plotted as a function of frequency then provide an indication as to whether adequate control authority is available to command the desired outputs by the available control inputs. At this stage, further dynamics are appended to the plant to provide desirable feedback-loop properties. An example of these augmentation dynamics is the addition of integrators in each control channel to ensure that the resultant system tracks step commands with zero steady-state error.

The control design structure consists of feedback control with command shaping, as shown in the block diagram of Fig. 1. Design goals are used to generate requirements on feedback-loop properties and on command shaping prefilters. The feedback compensator, $\mathrm{K}(\mathrm{s})$, is designed first using a Linear Quadratic Gaussian with Loop Transfer Recovery (LQG/LTR) ${ }^{[5,6]}$ approach. The LQG/LTR methodology provides an integrated frequency-domain and state-space approach for design of multi-input multi-output (MIMO) control systems and directly addresses design issues such as stability robustness and trade-off between performance and allowable control power. The basic requirements that the closed-loop feedback system must satisfy are : (1)Stability - bounded outputs, $y(s)$, for all bounded disturbances, $d(s)$, and bounded reference inputs, $r(s),(2)$ Performance 
- small errors, $e(s)$, in the presence of $r(s)$ and $d(s)$, and (3)Robustness - stability and performance maintained in the presence of model uncertainties. These requirements can be transformed into specifications on the form of the loop shapes for the feedback system. The LQG/LTR procedure then consists of synthesizing the feedback compensator, $\mathrm{K}(\mathrm{s})$, by manipulating the LQG design parameters in such a way that the desired loop shapes are obtained.

After the feedback design is complete, the command shaping, $\mathrm{P}(\mathrm{s})$, is designed with a multi-variable bandlimited inverse method ${ }^{[7]}$. This method is based on the theoretical asymptotic properties of the linear quadratic stochastic control problem and provides for setting the bandwidth of the prefiltering action by properly selecting the control weighting in the regulator problem. Such an approach allows the designer to obtain a prefilter, $\mathrm{P}(\mathrm{s})$, for desired response to command inputs without altering the feedback properties.

The command shaping and feedback compensator designs can performed for the various design points covering the aircraft flight envelope and a practical controller for the full flight envelope obtained by gain scheduling the designs, adding limiting functions, etc.. In this study, however, the control design will be performed for only one fixed point along the approach and landing trajectory.

A major criticism of a centralized IFPC design approach, such as the one discussed above, is that it results in one high order complicated compensator which is very difficult to implement. Such a compensator might also result in many feedback paths which are not physically realizable. Also, traditionally it is the responsibility of the engine designer/manufacturer to make sure that the engine will provide the desired performance when installed in the airframe. The engine manufacturer performs extensive "bench tests" with an active engine controller to assure an adequate design. The accountability issue, then, becomes a major political hurdle with a centralized airframe and engine compensator. To address these difficulties, the idea of partitioning the centralized compensator into separate airframe and engine sub-controllers, without any significant loss in overall system 
performance, is introduced in this paper. The mathematics associated with the compensator partitioning and the example application are discussed in a later section.

\section{Vehicle Model}

The vehicle model consists of an integrated airframe and propulsion system state-space representation for a modern fighter aircraft powered by a two-spool turbofan engine and equipped with a 2D thrust-vectoring and reversing nozzle. The vehicle dynamics are linearized at an airspeed $\mathrm{V}_{0}=120$ Knots and flight path angle $\gamma_{0}=-3$ deg. This flight condition is representative of the STOL (Short Take-off and Landing) approach-to-landing task. The vehicle model has the form

$$
\dot{\vec{x}}_{p}=A_{p} \bar{x}_{p}+B_{p} \bar{u}_{p} ; y_{p}=C_{p} \bar{x}_{p}+D_{p} \bar{u}_{p}
$$

where the state vector is

$$
\bar{x}_{p}=[u, w, q, \theta, h, N 2, N 25, P 6, T 41 B]^{T}
$$

with

$$
\begin{aligned}
& \mathrm{u}=\text { aircraft body axis forward velocity }(\mathrm{ft} / \mathrm{sec}) \\
& \mathrm{w}=\text { aircraft body axis vertical velocity }(\mathrm{ft} / \mathrm{sec}) \\
& \mathrm{q}=\text { aircraft pitch rate (rads/sec) } \\
& \theta=\text { pitch angle }(\mathrm{rads}) \\
& \mathrm{h}=\text { altitude (ft) } \\
& \mathrm{N} 2=\text { engine fan speed (rpm) } \\
& \mathrm{N} 25=\text { core compressor speed (rpm) } \\
& \mathrm{P} 6=\text { engine mixing plane pressure (psia) }
\end{aligned}
$$

$\mathrm{T} 41 \mathrm{~B}=$ engine high pressure turbine blade temp. $\left({ }^{\mathrm{O}} \mathrm{R}\right)$,

and the control input vector is

$$
\overline{\mathrm{u}}_{\mathrm{p}}=\left[\delta_{\mathrm{FL}}, \delta_{\mathrm{FT}}, \mathrm{WF}, \mathrm{A} 78, \mathrm{~A} 8, \delta_{\mathrm{TV}}\right]^{\mathrm{T}}
$$

with

$\delta_{\mathrm{FT}}=$ leading edge flap deflection angle(deg)

$\delta_{\mathrm{FL}}=$ trailing edge flap deflection angle (deg)

$\mathrm{WF}=$ engine main burner fuel flow rate $(\# / \mathrm{hr})$

$\mathrm{A} 78=$ thrust reverser port area $\left(\mathrm{in}^{2}\right)$

A8 = main nozzle throat area $\left(\right.$ in $\left.^{2}\right)$ 


$$
\delta_{\mathrm{TV}}=\text { nozzle thrust vectoring angle }(\mathrm{deg})
$$

The vector $\bar{y}_{\mathrm{p}}$ represents the outputs to be controlled and will be discussed later in this paper. The vehicle system matrix $A_{p}$ and the control effectiveness matrix $B_{p}$ are listed in the Appendix.

The open-loop vehicle eigenvalues are :

$$
\begin{gathered}
\lambda_{1}=0.07, \lambda_{2,3}=-0.09 \pm \mathrm{j} 0.23, \underline{\lambda_{4}=1.06}, \lambda_{5}=-1.47-\text { Airframe modes } \\
\lambda_{6}=-1.40, \lambda_{7}=-3.57, \lambda_{8}=-6.96, \lambda_{9}=-89.28-\text { Propulsion modes } .
\end{gathered}
$$

Note that the airframe is statically unstable with a highly unstable pitch mode. The open-loop plant $A_{p}$ matrix is full, i.e. the propulsion system states affect the airframe dynamics and vice versa, indicating that there is adequate airframe/propulsion interaction to warrant an integrated control design. Analysis of the control distribution matrix, $\mathrm{B}_{\mathrm{p}}$, indicated that the flaps, $\delta_{\mathrm{FL}}$ and $\delta_{\mathrm{FT}}$, and thrust vectoring, $\delta_{\mathrm{TV}}$, are primarily airframe controls with very little effect on the propulsion system dynamics, whereas the fuel flow, WF, and the area controls, A78 and A8, affect both the airframe and the engine dynamics. Thrust vectoring, $\delta_{\mathrm{TV}}$, is the primary pitch control while the flaps are direct-lift devices which provide direct control of the flight path angle.

For the STOL approach and landing task, it is desirable to provide the pilot with decoupled control of flight path and airspeed. Open-loop analyses of the plant indicated that it was not possible to provide flight path control independent of the pitch attitude control. Therefore, the control law design objective was chosen as that of providing independent control of pitch attitude and airspeed from pilot inputs with the flaps used to augment the aircraft flight path to pitch attitude $(\underset{\theta}{\gamma})$ response. The desirable flight path to pitch attitude response for the STOL task is

$$
\left.\frac{y_{(s)}}{\theta}\right|_{\text {desired }} \approx \frac{1 / \tau \theta_{2}}{\mathrm{~s}+1 / \tau_{\theta_{2}}}
$$

where (s) represents the Laplace operator. The Level I handling qualities requirements ${ }^{[8]}$ 
are that $1 / \tau_{\theta_{2}} \geq 0.7 \mathrm{sec}^{-1}$. From the numerator of the open-loop pitch attitude response to $\delta_{\mathrm{TV}}$ input, the value of $1 / \tau_{\theta_{2}}$ was found to be $0.27 \mathrm{sec}^{-1}$ indicating that flight path augmentation will be necessary to obtain an acceptable system. It was not at all clear as to how the LQG/LTR-based DMICS methodology could be used to formulate the problem in such a manner as to directly synthesize the desired flight path to attitude response. Therefore, prior to applying the DMICS methodology, classical single-input single-output control law design techniques were used to augment the flight path response. Since the flaps are direct lift devices, a constant gain loop closure from angle of attack to the flaps, i.e. $\delta_{\mathrm{FL}}=-\mathrm{K}_{1} \alpha$ and $\delta_{\mathrm{FT}}=-\mathrm{K}_{2} \alpha$ with $\alpha=\mathrm{C}_{\alpha} \overline{\mathrm{x}}_{\mathrm{p}}$, will effectively increase the value of ${ }^{1 / \tau} \theta_{2}$. The numerical value of matrix $\mathrm{C}_{\alpha}$ is listed in the Appendix. Based on open-loop evaluation of the effectiveness of the flaps, the gains $\mathrm{K}_{1}$ and $\mathrm{K}_{2}$ were chosen such that $\mathrm{K}_{2}=$ $-\mathrm{K}_{1}$. Based on the theory of coupling numerators ${ }^{[9]}$, the root-locus technique was used to study the effect of these loop closures on the zeros of the numerator of $\frac{\theta}{\delta_{\mathrm{TV}}}(\mathrm{s})$ transfer function. A detailed example of this procedure can be found in Ref. [10]. A value of $K_{1}=3$ $\mathrm{deg} / \mathrm{deg}$ resulted in $1 / \tau_{\theta_{2}}=0.52 \mathrm{sec}^{-1}$. Although $1 / \tau_{\theta_{2}}$ could be increased further by increasing $K_{1}$, doing so will result in excessive flap deflections. Therefore, $K_{1}=3 \mathrm{deg} / \mathrm{deg}$ was used as a reasonable compromise between handling quality requirements and flap deflection constraints. With the flap loops closed, the control inputs available for the feedback compensator design are

$$
\bar{u}_{\mathrm{p}}^{\prime}=\left[\mathrm{WF}, \mathrm{A} 78, \mathrm{~A} 8, \delta_{\mathrm{TV}}\right]^{\mathrm{T}} \text {. }
$$

For the rest of this paper, the vehicle model with the flap loops closed as above, will be considered to be the design model.

\section{Feedback Compensator Design and Evaluation}

The design specifications for the feedback compensator were chosen as follows:

(1) Track airframe and engine commands in a decoupled manner and with zero 
steady-state error for step commands.

(2) Maintain "adequate" stability margins in all control loops to guarantee stability in the presence of unmodelled dynamics and variation in model parameters.

(3) Avoid "excessive" control deflections and rates to prevent non-linearities due to control deflection and/or rate limiting.

As stated earlier, the control design objective is to provide the pilot with independent control of aircraft airspeed and pitch attitude. In the STOL mode, thrust reversing is used to allow higher frequency control of the forward velocity. To effectively use thrust reversing, the engine is maintained at Military power level. This power setting will use the engine fan speed (N2) and engine pressure ratio (EPR) set points from the baseline engine control schedule. Thus the airframe and engine outputs to be controlled are

$$
\bar{y}_{p}=\left[V, q_{v}, N 2 P, E P R\right]^{T}
$$

where

$\mathrm{V}=$ aircraft airspeed $(\mathrm{ft} / \mathrm{sec})$

$\mathrm{q}_{\mathrm{v}}=$ pitch variable $=\mathrm{q}+0.1 \theta$

$\mathrm{N} 2 \mathrm{P}=$ engine fan speed ( $\%$ of maximum allowable rpm at operating condition)

$\mathrm{EPR}=$ engine pressure ratio

The $\mathrm{C}_{\mathrm{p}}$ matrix corresponding to these outputs is listed in the Appendix, and the $\mathrm{D}_{\mathrm{p}}$ matrix is $\overline{0}$. Note that the choice of $\mathrm{q}_{\mathrm{v}}$ above reflects the desire to track pitch rate commands at high frequencies and pitch attitude commands at low frequencies. This choice is consistent with the work reported in Ref. [4].

Based on performance requirements, stability robustness to unmodelled dynamics such as actuators and sensors, and the open-loop analyses of control effectiveness, the desired control bandwidths were chosen as $1 \mathrm{rads} / \mathrm{sec}$ for the $\mathrm{V}$ loop, 5 rads/sec for the $\mathrm{q}_{\mathrm{V}}$ loop, 5 rads/sec for the N2 loop and 10 rads/sec for the EPR loop.

As pointed out in an earlier section, and vividly brought forth by an example study in Ref. [11], it is very important to properly scale the system of Eqn. (1) prior to applying 
the LQG/LTR methodology in order for the methodology to lead to the desired results. For the present study, an input/output scaling of the following form was used

$$
\bar{u}_{p_{s}}=S_{u} \bar{u}_{p}^{\prime} ; \bar{y}_{p_{s}}=S_{y} \bar{y}_{p}
$$

resulting in a scaled system of the form

$$
\dot{\bar{x}}_{\mathrm{p}}=\mathrm{A}_{\mathrm{p}}^{\prime} \overline{\mathrm{x}}_{\mathrm{p}}+\mathrm{B}_{\mathrm{p}_{\mathrm{s}}} \overline{\mathrm{u}}_{\mathrm{p}_{\mathrm{s}}} ; \overline{\mathrm{y}}_{\mathrm{p}_{\mathrm{s}}}=\mathrm{C}_{\mathrm{p}_{\mathrm{s}}} \overline{\mathrm{x}}_{\mathrm{p}}
$$

where $\mathrm{B}_{\mathrm{p}_{\mathrm{s}}}=\mathrm{B}_{\mathrm{p}}^{\prime} \mathrm{S}_{\mathrm{u}}^{-1}$ and $\mathrm{C}_{\mathrm{p}_{\mathrm{s}}}=\mathrm{S}_{\mathrm{y}} \mathrm{C}_{\mathrm{p}}$. Here, $\mathrm{B}_{\mathrm{p}}^{\prime}$ is the control distribution matrix corresponding to the control inputs $\bar{u}_{p}^{\prime}$, and $A_{p}^{\prime}$ is the plant matrix with the flap loops closed. The numerical values of $\mathrm{S}_{\mathrm{u}}$ and $\mathrm{S}_{\mathrm{y}}$ correspond to normalizing the control inputs by their maximum allowable variations from trim and the controlled outputs by the maximum values to be commanded, are listed in the Appendix.

Since the vehicle model has no integrators, and a zero steady-state error for step commands is desired, integral control action (see Ref. [12]) is provided by appending four integrators to the plant - one in each control channel. The augmented plant has the form

$$
\dot{\overline{\mathrm{x}}}=\mathrm{A} \overline{\mathrm{x}}+\mathrm{B} \overline{\mathrm{u}} ; \overline{\mathrm{y}}=\mathrm{C} \overline{\mathrm{x}}
$$

where $\bar{x}=\left[\bar{x}_{p}^{T}, \bar{u}_{p_{s}}^{T}\right]^{T}$ with $\bar{x}_{p}$ and $\bar{u}_{p_{s}}$ as defined before, and $\bar{y} \equiv \bar{y}_{p_{s}}$. The system matrices $\mathrm{A}, \mathrm{B}$ and $\mathrm{C}$ for the scaled, augmented plant are given by :

$$
\mathrm{A}=\left[\begin{array}{cc}
\mathrm{A}_{\mathrm{p}}^{\prime} & \mathrm{B}_{\mathrm{p}_{\mathrm{s}}} \\
0 & 0
\end{array}\right] ; \mathrm{B}=\left[\begin{array}{l}
0 \\
\mathrm{I}
\end{array}\right] ; \mathrm{C}=\left[\mathrm{C}_{\mathrm{p}_{\mathrm{s}}} 0\right]
$$

where I is an appropriately dimensioned identity matrix.

The LQG/LTR procedure is based on solving for the optimal compensator that minimizes the performance index

$$
\mathrm{J}_{\mathrm{p}}=\mathrm{E}\left\{\lim _{\mathrm{T} \rightarrow \infty} \frac{1}{\mathrm{~T}} \int_{0}^{\mathrm{T}}\left[\left(\overline{\mathrm{z}} \mathrm{T}_{\overline{\mathrm{z}}}+\mathrm{p} \overline{\mathrm{y}} \mathrm{T} \mathrm{y}\right)+\rho \overline{\mathrm{u}}^{\mathrm{T}} \mathrm{u}\right] \mathrm{dt}\right\}
$$

for a system of the form

$$
\begin{gathered}
\dot{\bar{x}}=A \bar{x}+B \bar{u}+\Gamma \bar{\xi} \\
\bar{y}=C \bar{x}+\nu \bar{I} \bar{\eta} \quad ; \quad \bar{z}=H \bar{x}
\end{gathered}
$$

where $\bar{\xi}$ and $\bar{\eta}$ are zero-mean Gaussian white-noise processes with identity intensity, $\overline{\mathrm{y}}$ are 
the measurements available as compensator inputs, and $\bar{z}$ are the controlled plant outputs. $\mathrm{V}$ is any positive definite symmetric weighting matrix, and $\nu, \mathrm{p}, \rho$ and the process noise distribution matrix $\Gamma$ are the design parameters that are used in the LQG/LTR procedure to synthesize a compensator that would meet the desired specifications. The procedure consists of first designing the Kalman filter such that the filter loop satisfies the performance and stability robustness requirements, and then recovering this loop asymptotically by tuning the regulator. The Kalman filter gains $\mathrm{K}_{\mathrm{F}}$ and the regulator gains $K_{C}$ are obtained by solving their respective algebraic Riccati equations ${ }^{[12]}$. The LQG/LTR compensator has the form

$$
\mathrm{K}_{\mathrm{LQG} / \mathrm{LTR}}(\mathrm{s})=\mathrm{K}_{\mathrm{C}}{ }^{[\mathrm{sI}-(\mathrm{A}-\mathrm{BK}} \mathrm{C}^{\left.\left.-\mathrm{K}_{\mathrm{F}} \mathrm{C}\right)\right]^{-1} \mathrm{~K}_{\mathrm{F}}}
$$

Detailed discussion of how to choose the LQG/LTR design parameters is available in various application studies of the LQG/LTR methodology, see for example Refs. [13] and [14]. For instance, it is shown that if the Kalman filter loop is to meet the design specifications, then $\Gamma$ and $\nu$ shall be selected in such a way that the Target Feedback Loop transfer function matrix $\mathrm{G}_{\mathrm{FOL}}(\mathrm{s})$, defined as

$$
\mathrm{G}_{\mathrm{FOL}}(\mathrm{s})=\left(\frac{1}{\sqrt{\nu}}\right) \mathrm{C}(\mathrm{sI}-\mathrm{A})^{-1} \Gamma
$$

has the desired loop shapes. From the design specifications stated earlier, the requirement on $\mathrm{G}_{\mathrm{FOL}}(\mathrm{s})$ is

$$
\mathrm{G}_{\mathrm{FOL}}(\mathrm{s}) \cong \frac{1}{\mathrm{~s}} \cdot \operatorname{diag}[1,5,5,10]
$$

i.e. bandwidth of $1,5,5$, and $10 \mathrm{rads} / \mathrm{sec}$ for the $\mathrm{V}, \mathrm{q}_{\mathrm{v}}, \mathrm{N} 2$ and EPR loops respectively, $\mathrm{k} / \mathrm{s}$ behavior at loop cross-over for stability robustness, and large low-frequency gains for accurate steady-state tracking of commands.

For the IFPC control problem being considered here, the controlled variables are the same as the measurements, i.e. $\mathrm{H}=\mathrm{C}$, and the matrices $\mathrm{A}, \mathrm{B}$ and $\mathrm{C}$ are as defined in (4). The singular values of the augmented, scaled plant $\left(\sigma_{\mathrm{i}}[\mathrm{G}(\mathrm{j} \omega)]\right.$ with $\left.G(j \omega)=C(j \omega I-A)^{-1} B\right)$ are shown in Fig. 2. These indicate that the design plant $G(s)$ has 
the desired loop shapes, so the choice $\Gamma=B$ can be used in (8) to define the Target Feedback Loop $\mathrm{G}_{\mathrm{FOL}}(\mathrm{s})$ in the synthesis of the Kalman filter gains $\mathrm{K}_{\mathrm{F}}$. The block diagram for the LQG/LTR compensator design is shown in Fig. 3. In Fig. 3, $\mathrm{G}_{\mathrm{p}}(\mathrm{s})$ is the transfer function matrix of the vehicle model with the flap loops closed. With $\rho=1$ and $\mathrm{V}$ $=\mathrm{I}$, in (5), an LQG/LTR compensator that satisfies the desired command tracking bandwidth requirements was obtained for the design parameter values $\nu=0.64$ and $\mathrm{p}=$ $10^{4}$. Note that although choosing a higher value of $\mathrm{p}$ would have led to a better recovery of the Kalman filter loop and the associated guaranteed stability margins, doing so would also have resulted in larger control bandwidth requirements. The singular values of the loop transfer matrix at the plant output $\left(\sigma_{\mathrm{i}}[\mathrm{GK}(\mathrm{j} \omega)]\right.$ with $\left.\mathrm{K}(\mathrm{j} \omega)=\mathrm{K}_{\mathrm{LQG} / \mathrm{LTR}}(\mathrm{j} \omega)\right)$ are shown in Fig. 4. In Fig. 4, the large loop gains at low frequencies indicate the desirable properties of good command tracking and disturbance rejection, and the loop bandwidths are from 1 to $10 \mathrm{rads} / \mathrm{sec}$ providing adequate roll-off at higher frequencies to maintain stability in the presence of unmodelled dynamics. Detailed closed-loop performance and stability robustness evaluation results with this design compensator are presented in the following.

The closed-loop system tracking performance was evaluated by studying the Bode plots of the closed-loop system frequency response to commanded inputs, and time histories of closed-loop response to step commanded inputs. The frequency response of velocity $\mathrm{V}$ to all the commanded inputs $\left(\mathrm{V}_{\mathrm{c}}, \mathrm{q}_{\mathrm{v}_{\mathrm{c}}}, \mathrm{N}_{\mathrm{C}} \mathrm{P}_{\mathrm{c}}\right.$ and $\left.\mathrm{EPR}_{\mathrm{c}}\right)$ is shown in Fig. 5 as an example of the Bode plots that were studied. Note that the quantities shown in Fig. 5 are scaled quantities (corresponding to $\overline{\mathrm{y}}_{\mathrm{p}_{\mathrm{s}}}$ and $\overline{\mathrm{y}}_{\mathrm{S}_{\mathrm{c}}}$ of Fig. 3), so that the response magnitudes can be compared one-to-one to assess the degree of coupling/decoupling in the closed-loop system response. As seen from Fig. 5, the feedback compensator provides accurate tracking of velocity commands up to a bandwidth of $1.8 \mathrm{rads} / \mathrm{sec}$ (here, bandwidth is defined as the frequency at which the response magnitude of the primary commanded variable is $-3 \mathrm{~dB}$ ) with insignificant response in velocity to other commanded variables. The bandwidths of the $\mathrm{q}_{\mathrm{v}}, \mathrm{N} 2$ and EPR loops were $11,6.9$ and 8.7 rads/sec respectively. The larger than 
desired bandwidths for tracking the $\mathrm{V}, \mathrm{q}_{\mathrm{v}}$, and $\mathrm{N} 2$ commands are acceptable as long as these do not require large bandwidths for control deflections and/or lead to instability in the presence of unmodelled dynamics. The discrepancy between the desired bandwidth for EPR (10 rads/sec) and the achieved bandwidth $(8.7 \mathrm{rads} / \mathrm{sec})$ was not severe enough to warrant a redesign. The time-domain analysis of closed-loop system response to step commands also showed decoupled command tracking with well-damped response and fast rise times for the $\mathrm{q}_{v}$, N2 and EPR responses. Note that apart from good command tracking performance, it is also important to make sure that the feedback compensator does not result in excessive variations in other variables such as compressor and turbine stall margins, high pressure temperature turbine blade etc., which are of interest from the point of safe operation of the engine. The responses of these variables were studied for the present compensator design, and were found to be within allowable limits for maximum step commands in the controlled variables.

Extensive stability robustness studies, using the singular value approach ${ }^{[15,16]}$, were performed for this feedback compensator design. The effect on closed-loop system stability due to including some representative actuator and sensor dynamics was first studied. The design plant $\mathrm{G}(\mathrm{s})$ was augmented with the following sensor and actuator dynamics

$$
\begin{aligned}
& \text { Sensors: } \quad \mathrm{N} 22_{\mathrm{s}}=\frac{20}{\mathrm{~s}+20} \mathrm{~N} 2 \quad ; \quad \mathrm{EPR}_{\mathrm{s}}=\frac{100}{\mathrm{~s}+100} \mathrm{EPR} \\
& \text { Actuators: } \quad \mathrm{WF}=\frac{10}{\mathrm{~s}+10} \cdot \frac{50}{\mathrm{~s}+50} \mathrm{WF}_{\mathrm{c}} \\
& \mathrm{A}=\frac{(30)^{2}}{\mathrm{~s}^{2}+2(0.5)(30) \mathrm{s}+(30)^{2}} \cdot \frac{100}{\mathrm{~s}+100} \mathrm{~A}_{\mathrm{c}} \text { for Areas A78 and A8 } \\
& \delta_{\mathrm{TV}}=\frac{15}{\mathrm{~s}+15} \delta_{\mathrm{TV}}
\end{aligned}
$$

to obtain the higher order "truth" model $G_{0}(s)$. The error between the "truth" model and the design model was defined as multiplicative error at the plant output leading to the following definitions : 


$$
\mathrm{G}_{\mathrm{o}}(\mathrm{s})=[\mathrm{I}+\mathrm{E}(\mathrm{s})] \mathrm{G}(\mathrm{s}) \Rightarrow \mathrm{E}(\mathrm{s})=\left[\mathrm{G}_{\mathrm{o}}(\mathrm{s})-\mathrm{G}(\mathrm{s})\right] \mathrm{G}^{-1}(\mathrm{~s})
$$

The stability of the closed-loop system for the "truth" model is guaranteed if the following singular value condition is satisfied for all frequencies $\omega$ :

$$
\underline{\sigma}\left[\mathrm{I}+(\mathrm{GK}(\mathrm{j} \omega))^{-1}\right]>\bar{\sigma}[\mathrm{E}(\mathrm{j} \omega)]
$$

In inequality (11), $\underline{\sigma}$ refers to the minimum singular value, $\bar{\sigma}$ refers to the maximum singular value, and $\mathrm{I}+(\mathrm{GK})^{-1}$ is the inverse return difference transfer matrix at the design plant output $(\overline{\mathrm{y}})$. The two quantities in (11) are compared in Fig. 6. From Fig. 6 we note that the stability condition (11) is violated in the frequency region 15 to 30 rads/sec. However, eigenvalue analysis of the closed-loop system with the "truth" model and the design LQG/LTR compensator showed the closed-loop system to be stable, thus pointing to the conservativeness of the singular value analysis approach. Clearly, then, there is a need to develop improved procedures for stability robustness analysis of multivariable systems.

Lehtomaki et al. ${ }^{[16]}$ have shown that for multi-input multi-output systems, the minimum singular value of the return difference matrix, calculated at the plant output or input, is a reliable measure of closed-loop system stability robustness to unstructured uncertainties occurring at the plant input or output. For the present feedback compensator design, the lowest value of the minimum singular value of the return difference matrix at the design plant output $(\underline{\sigma}[\mathrm{I}+\mathrm{GK}(\mathrm{j} \omega)])$ was 0.72 and that at the design plant input $(\underline{\sigma}[\mathrm{I}+\mathrm{KG}(\mathrm{j} \omega)])$ was 0.65 . These values indicate reasonable stability robustness to unstructured uncertainties. (Note that if the loop recovery parameter p was chosen to be large enough such that the filter loop is completely recovered, then we will have $\underline{\sigma}[\operatorname{I+GK}(\mathrm{j} \omega)] \geq 1)$. However, it is important to realize that these stability robustness properties are guaranteed for the loops broken at the points (1) and (2) in the LQG/LTR compensator design block diagram of Fig. 3. The actual control system implementation will be as shown in the block diagram of Fig. 7, wherein the interface between the physical system $\left(G_{p}(s)=C_{p}\left(s I-A_{p}^{\prime}\right)^{-1} B_{p}^{\prime}\right.$ for the present case) and the control system $\left(K_{p}(s)\right)$ is at 
points $\left(1^{\prime}\right)$ and $\left(2^{\prime}\right)$. It is at these points in the loop that we need "good" stability margins. The lowest value of the minimum singular value of the return difference matrix at points $\left(1^{\prime}\right)$ and $\left(2^{\prime}\right)$, minimum over $\omega$ of $\underline{\sigma}\left[\mathrm{I}+\mathrm{K}_{\mathrm{p}} \mathrm{G}_{\mathrm{p}}(\mathrm{j} \omega)\right]$ and $\underline{\sigma}\left[\mathrm{I}+\mathrm{G}_{\mathrm{p}} \mathrm{K}_{\mathrm{p}}\right]$ respectively, were found to be 0.02 and 0.1 respectively. These values indicate very poor stability robustness to unstructured uncertainties for the system as implemented in Fig. 7. From this analysis it would appear that the claim that the LQG/LTR methodology recovers the guaranteed stability robustness properties of the LQR (Linear Quadratic Regulator) problem is misleading. The stability robustness properties are recovered, but not at the physical interface between the plant and the control system where the effect of the modeling uncertainties will actually occur.

In control system design, a classical measure of stability robustness are the gain and phase margins ${ }^{[17]}$. Although the above results indicate that the implementation system (as in Fig. 7) will have much reduced stability robustness with respect to unstructured uncertainties as compared to the design system (as in Fig. 3), it has been shown in Ref. [11] that as far as structured uncertainty in the form of loop gain or phase variations is concerned, the implementation system will have the same guaranteed multivariable stability margins as obtained for the design system. This result is based on a nonconservative measure of stability robustness for structured uncertainties, called $\mu$ or the structured singular value, that has recently been developed ${ }^{[18,19]}$. A detailed mathematical discussion of the definition and properties of $\mu$, and the form of structured uncertainties that can be analyzed using $\mu$ can be found in Ref. [18]. For the case of loop gain or phase variations, this stability robustness measure is given by

$$
\mu[\mathrm{M}(\mathrm{j} \omega)]=\min _{\mathrm{D} \in \boldsymbol{D}} \underline{\sigma}\left[\mathrm{DM}(\mathrm{j} \omega) \mathrm{D}^{-1}\right]
$$

where $M$ is the return difference matrix at the loop point where the gain or phase variations are being considered (for example, $M=I+K G(j \omega)$ for point (1) of Fig. 3), and $D$ is the set of all real diagonal matrices. In Ref. [19], it is shown that if 


$$
\mu[\mathrm{M}(\mathrm{j} \omega)] \geq \mu_{\min }, 0<\omega<\infty
$$

for some constant $\mu_{\min } \leq 1$, then the nonconservative guaranteed multivariable gain and phase margins are given by

$$
\begin{aligned}
& \text { Gain Margin : } \mathrm{GM}=\frac{1}{1 \pm \mu_{\min }} \\
& \text { Phase Margin : } \mathrm{PM}= \pm 2 \sin ^{-1}\left(\frac{\mu_{\mathrm{min}}}{2}\right)
\end{aligned}
$$

For the special case of gain and phase variations being considered here, the optimal matrix $\mathrm{D}^{*}$ corresponding to the minimum structured singular value $\mu$ in Eqn. (12) at each frequency $\omega$ can be obtained using a globally convergent algorithm developed by Osborne ${ }^{[20]}$. This algorithm was applied to the return difference transfer matrices at points (1) and (2) with the design LQG/LTR compensator, and resulted in $\mu_{\min }=0.71$ at the plant input and $\mu_{\min }=0.73$ at the plant output. Using (14), these results imply that the closed-loop system will have guaranteed multivariable gain margins of $-4.7 \mathrm{~dB}$ to $11.1 \mathrm{~dB}$ and phase margins of $\pm 42.4 \mathrm{deg}$ for simultaneous gain or phase variations at the plant input or the output. These are excellent stability margins and meet the military specifications for the operation of flight vehicles.

The stability robustness of the closed-loop system as implemented in Fig. 7 was further evaluated by using the more "classical" approach of "breaking" one loop at a time (i.e., one loop open and the other loops closed). An example Bode plot for the loop broken at the plant input WF is shown in Fig. 8. As seen from Fig. 8, the closed-loop system will remain stable for gain increase of up to $15 \mathrm{~dB}$ or additional phase lag of up to $50^{\circ}$ in the WF loop with all other loops closed at nominal design values. The one-loop-at-a-time analysis revealed equally good gain and phase margins for individual variations in the other input as well as output loops.

The one-loop-at-a-time analysis is also useful in studying the integrity of the system with respect to actuator and sensor failures, and the actuator bandwidth requirements for the control loops. The present design was found to be unstable for failure 
in the $\mathrm{q}_{\mathrm{V}}$ and $\mathrm{N} 2$ loops, and the A78, A8 and $\delta_{\mathrm{TV}}$ loops, thus indicating the need to provide adequate redundancy in the corresponding sensors and actuators to ensure fail-safe operation. The control bandwidths (defined as the loop crossover frequency, for example $\omega_{\mathrm{C}}$ in Fig. 8) for the WF, A78, A8 and $\delta_{\mathrm{TV}}$ loops were 3.2, 1.7, 2.6 and 6.2 rads/sec respectively. These control requirements are very much within the actuator bandwidths for the representative actuators considered earlier in the stability robustness study. The control deflection and rate requirements for tracking maximum commanded values of the controlled variables, obtained from time histories of the control input $\left(\bar{u}_{p}^{\prime}\right)$ responses to step commands $\left(\overline{\mathrm{y}}_{\mathrm{p}_{\mathrm{c}}}\right)$, were also found to be reasonable and within the maximum allowable control deflections and rates.

\section{Compensator Partitioning and Simplification}

The need to separately implement controllers for the airframe and the engine was pointed out in an earlier section. In this section, the mathematical approach to partitioning the high-order integrated compensator into separate sub-system controllers is presented along with the numerical results for partitioning the LQG/LTR compensator obtained in the previous section. The partitioned sub-controllers are further reduced in state dimension and simplified for ease of implementation. Some example results are then presented to compare the closed-loop system performance and robustness for these simplified sub-controllers with that for the full-order LQG/LTR compensator. Note that partitioning the integrated compensator and then reducing the order of the sub-controllers is intuitively more meaningful than reducing the order of the integrated compensator before partitioning. In the latter case, any decoupling inherent in the compensator due to the decoupled behavior of the integrated system (plant) might be lost in the process of reducing the order of the compensator, thus making the partitioning task more difficult. Moreover, reducing the order of the sub-controllers would be easier computationally as these would already be of lower order than the integrated compensator. 


\section{Compensator Partitioning}

The mathematical approach to partitioning the integrated compensator into separate (state-decoupled) sub-controllers, presented in the following, was motivated by the discussion in Ref. [2] on partitioning the integrated system (plant) into state-decoupled sub-systems so as to perform the decentralized, hierarchical control system design. For ease of discussion and relevance to the present design study, the procedure is presented for partitioning into just two sub-controllers, those for the airframe and the engine. The procedure, however, is clearly applicable for the more general case of more than two sub-controllers. The direct feedthrough term $\left(D_{c}\right)$, for the compensator, has also been neglected in the following to keep the equations simple. The extension to the case of the non-zero $\mathrm{D}_{\mathrm{C}}$ matrix is quite straightforward.

Given an integrated compensator of the form

$$
\dot{\bar{x}}_{\mathrm{c}}=\mathrm{A}_{\mathrm{c}} \overline{\mathrm{x}}_{\mathrm{c}}+\mathrm{B}_{\mathrm{c}} \overline{\mathrm{e}}_{\mathrm{y}} ; \overline{\mathrm{u}}=\mathrm{C}_{\mathrm{c}} \overline{\mathrm{x}}_{\mathrm{c}}
$$

we want to obtain state-decoupled sub-controllers of the form

$$
\begin{array}{ll}
\text { Airframe } & \dot{\bar{x}}_{c_{a}}=A_{c_{a}} \bar{x}_{c_{a}}+B_{c_{a}} \bar{e}_{y_{a}}+\Gamma_{a e} \bar{e}_{y_{e}} \\
\text { Controller }: & \bar{u}_{a}=C_{c_{a}} \bar{x}_{c_{a}}+W_{a e} \overline{\bar{u}}_{e}
\end{array}
$$

and

$$
\begin{array}{ll}
\text { Engine } & \dot{\bar{x}}_{c_{e}}=A_{c_{e}} \bar{x}_{c_{e}}+B_{c_{e}} \bar{e}_{y_{e}}+\Gamma_{e a} \bar{e}_{y_{a}} \\
\text { Controller }: & \bar{u}_{e}=C_{c_{e}} \bar{x}_{c_{e}}+W_{e a} \bar{u}_{a}
\end{array}
$$

with $\overline{\mathrm{u}}^{\mathrm{T}}=\left[\mathrm{u}_{\mathrm{a}}^{\mathrm{T}}, \overline{\mathrm{u}}_{\mathrm{e}}^{\mathrm{T}}\right]$ and $\overline{\mathrm{e}}_{\mathrm{y}}^{\mathrm{T}}=\left[\mathrm{e}_{\mathrm{y}_{\mathrm{a}}}^{\mathrm{T}}, \overline{\mathrm{e}}_{\mathrm{y}_{\mathrm{e}}}^{\mathrm{T}}\right]$, such that the input-output behavior ( $\overline{\mathrm{u}}$ to $\overline{\mathrm{e}}_{\mathrm{y}}$ response) of the integrated compensator is matched as best as possible. This desired partitioning is shown in the simplified block diagrams of Fig. 9. Note that with such a partitioning, the states of one sub-controller do not directly affect the outputs of the other sub-controller. Therefore the sub-controllers can be built as separate "black-boxes" and integrated in the final implementation with the least number of interconnections. The division of the integrated compensator inputs $\left(\overline{\mathrm{e}}_{\mathrm{y}}\right)$ and outputs $(\overline{\mathrm{u}})$ into the respective 
sub-controller inputs $\left(\bar{e}_{y_{a}}\right.$ and $\left.\bar{e}_{y_{e}}\right)$ and outputs $\left(\bar{u}_{a}\right.$ and $\left.\bar{u}_{e}\right)$ is determined based on the results of the open-loop control effectiveness analyses, conducted at the initialization of the control design study. This is coupled with an intimate knowledge of the physical system being controlled, i.e. the control inputs $\bar{u}_{a}$ into the integrated plant $(G(s))$ are primarily effective in regulating the errors $\overline{\mathrm{e}}_{\mathrm{y}_{\mathbf{a}}}$ with secondary response in the errors $\overline{\mathrm{e}}_{\mathrm{y}}$, and similarly for $\overline{\mathrm{u}}_{\mathrm{e}}$.

The state definition of the integrated compensator has no particular significance in terms of physical interpretation. Therefore, without loss of generality, the eqns. (15) can be assumed to be in the modal form so that the matrix $A_{c}$ is block diagonal. The matrices $B_{c}$ and $\mathrm{C}_{\mathrm{C}}$ are then measures of the modal controllability and observability respectively for the compensator modes. The modal compensator states $\overline{\mathrm{x}}_{\mathrm{c}}$ are assigned to $\overline{\mathrm{x}}_{\mathrm{a}}$ or $\overline{\mathrm{x}}_{\mathrm{e}}$ based on whether they are more controllable by $\overline{\mathrm{e}}_{\mathrm{y}_{a}}$ or $\overline{\mathrm{e}}_{\mathrm{ye}_{\mathrm{e}}}$ and/or more observable in $\overline{\mathrm{u}}_{\mathrm{a}}$ or $\overline{\mathrm{u}}_{\mathrm{e}}$. This is accomplished by considering the columns of $\mathrm{B}_{\mathrm{c}}$ and rows of $\mathrm{C}_{\mathrm{c}}$ one at a time and comparing the relative magnitudes of the elements in the columns/rows. From eqns. (15) to (17), note that all the integrated compensator inputs $\left(\overline{\mathrm{e}}_{\mathrm{y}}\right)$ are also inputs to the state equations of the sub-controllers. This means that the modal controllability for the integrated compensator is perfectly matched in the partitioning. Therefore in case of a conflict in assigning the integrated compensator states to $\overline{\mathrm{x}}_{\mathrm{a}}$ or $\overline{\mathrm{x}}_{\mathrm{e}}$, such as the case where a modal state is "most" controllable by an element of $\overline{\mathrm{e}}_{\mathrm{y}_{\mathrm{a}}}$ whereas it is "most" observable in an element of $\bar{u}_{e}$, the assignation should be based on observability. After the division and an appropriate re-ordering of the compensator modal states, the state-space representation for the compensator is as follows

$$
\left[\begin{array}{l}
\dot{\bar{x}}_{c_{a}} \\
\dot{\bar{x}}_{c_{e}}
\end{array}\right]=\left[\begin{array}{ll}
A_{c_{1}} & 0 \\
0 & A_{c_{2}}
\end{array}\right]\left[\begin{array}{l}
\bar{x}_{c_{a}} \\
\bar{x}_{c_{e}}
\end{array}\right]+\left[\begin{array}{ll}
B_{c_{11}} & { }_{c_{12}} \\
B_{c_{21}} & B_{c_{22}}
\end{array}\right]\left[\begin{array}{l}
\bar{e}_{y_{a}} \\
\bar{e}_{y_{e}}
\end{array}\right]
$$




$$
\left[\begin{array}{l}
\bar{u}_{\mathrm{a}} \\
\bar{u}_{\mathrm{e}}
\end{array}\right]=\left[\begin{array}{ll}
\mathrm{C}^{c_{11}} & \mathrm{C}_{\mathrm{c}_{12}} \\
\mathrm{C}_{\mathrm{c}_{21}} & \mathrm{C}_{\mathrm{c}_{22}}
\end{array}\right]\left[\begin{array}{l}
\overline{\mathrm{x}}_{\mathrm{c}_{\mathrm{a}}} \\
\overline{\mathrm{x}}_{\mathrm{c}_{\mathrm{e}}}
\end{array}\right]
$$

From a direct comparison of eqns (16) and (17) with eqn. (18), we get: $A_{C_{a}}=A_{C_{1}}$, $\mathrm{B}_{\mathrm{c}_{\mathrm{a}}}=\mathrm{B}_{\mathrm{c}_{11}}, \Gamma_{\mathrm{ae}}=\mathrm{B}_{\mathrm{c}_{12}}$, and $\mathrm{A}_{\mathrm{c}_{\mathrm{e}}}=\mathrm{A}_{\mathrm{c}_{2}}, \mathrm{~B}_{\mathrm{c}_{\mathrm{e}}}=\mathrm{B}_{\mathrm{c}_{22}}$ and $\Gamma_{\mathrm{ea}}=\mathrm{B}_{\mathrm{c}_{21}}$. So the only approximation involved in the partitioning is that of approximating the contribution of the states of one sub-controller to the outputs of the other sub-controller. Simple algebraic manipulation of eqns. (16) to (18) leads to the following solution:

$$
\begin{array}{ll}
\mathrm{W}_{\mathrm{ae}}=\mathrm{C}_{\mathrm{c}_{12}} \mathrm{C}_{\mathrm{c}_{22}}^{\#} ; \mathrm{C}_{\mathrm{c}_{\mathrm{a}}}=\mathrm{C}_{\mathrm{c}_{11}}-\mathrm{W}_{\mathrm{ae}} \mathrm{C}_{\mathrm{c}_{21}} \\
\mathrm{~W}_{\mathrm{ea}}=\mathrm{C}_{\mathrm{c}_{21}} \mathrm{C}_{\mathrm{c}_{11}}^{\#} ; \mathrm{C}_{\mathrm{c}_{\mathrm{e}}}=\mathrm{C}_{\mathrm{c}_{22}}-\mathrm{W}_{\mathrm{ea}} \mathrm{C}_{\mathrm{c}_{12}}
\end{array}
$$

In $(19),(\cdot)^{\#}$ denotes pseudo-inverse of $(\cdot)$. For numerical accuracy, singular value decomposition based procedures ${ }^{[21]}$ are used to solve for the pseudo-inverse.

For the LQG/LTR design compensator being considered here, from Fig. 3 the compensator inputs are the scaled tracking errors, i.e. $\overline{\mathrm{e}}_{\mathrm{y}}=\left[\mathrm{e}_{\mathrm{V}_{\mathrm{s}}}, \mathrm{e}_{\mathrm{q}_{\mathrm{vs}}}, \mathrm{e}_{\mathrm{N} 2 \mathrm{P}_{\mathrm{s}}}, \mathrm{e}_{\mathrm{EPR}_{\mathrm{s}}}\right]^{\mathrm{T}}$ with $\mathrm{e}_{\mathrm{V}_{\mathrm{s}}} \equiv \mathrm{V}_{\mathrm{c}_{\mathrm{s}}}-\mathrm{V}_{\mathrm{s}}$, and similarly for other errors with $(\cdot)_{\mathrm{s}}$ denoting scaled quantities. The LQG/LTR compensator outputs are the derivatives of the scaled plant control inputs, i.e. $\overline{\mathrm{u}}=\left[\mathrm{W} \dot{\mathrm{F}}_{\mathrm{s}}, \mathrm{A} \dot{7}_{\mathrm{s}}, \mathrm{A} \dot{8}_{\mathrm{s}}, \dot{\delta}_{\mathrm{TV}_{\mathrm{s}}}\right]^{\mathrm{T}}$, and the compensator is of $13^{\text {th }}$ order, i.e. $\operatorname{dim}\left(\overline{\mathrm{x}}_{\mathrm{c}}\right)=13$. Earlier open-loop analyses indicated that $\delta_{\mathrm{TV}}$ is primarily a pitch effector while WF, A78 and A8 mainly affect the engine control variables (N2 and EPR) and the airspeed (V). Therefore, the following sub-controller input/output pairings were chosen for compensator partitioning :

$$
\begin{aligned}
& \overline{\mathrm{e}}_{\mathrm{y}_{\mathrm{a}}}=\mathrm{e}_{\mathrm{qus}_{\mathrm{s}}} ; \overline{\mathrm{u}}_{\mathrm{a}}=\dot{\delta}_{\mathrm{TV} \mathrm{s}} \\
& \overline{\mathrm{e}}_{\mathrm{ye}_{\mathrm{e}}}=\left[\mathrm{e}_{\mathrm{V}_{\mathrm{s}}}, \mathrm{e}_{\mathrm{N}_{2} \mathrm{P}_{\mathrm{s}}}, \mathrm{e}_{\mathrm{EPR}_{\mathrm{s}}}\right]^{\mathrm{T}} ; \overline{\mathrm{u}}_{\mathrm{e}}=\left[\mathrm{W} \dot{\mathrm{F}}_{\mathrm{s}}, \mathrm{A} \dot{78_{\mathrm{s}}}, \mathrm{A} \dot{8}_{\mathrm{s}}\right]^{\mathrm{T}}
\end{aligned}
$$

The compensator modal controllability/observability studies, as discussed earlier, resulted in a $5^{\text {th }}$ order airframe sub-controller $\left(\operatorname{dim}\left(\bar{x}_{c_{a}}\right)=5\right)$ and an $8^{\text {th }}$ order engine sub-controller $\left(\operatorname{dim}\left(\bar{x}_{c_{e}}\right)=8\right)$. This compensator partitioning was validated by comparing 
the LQG/LTR compensator singular values $\left(\sigma_{\mathrm{i}}\left[\mathrm{K}_{\mathrm{LQG}} / \mathrm{LTR}(\mathrm{j} \omega)\right]\right)$ with the singular values of the integrated compensator obtained by assembling the partitioned sub-controllers (i.e. combining (16) and (17) in the form of (15)), and the singular values of the corresponding loop transfer matrices $\left(\sigma_{\mathrm{i}}[\mathrm{GK}(\mathrm{j} \omega)]\right)$ and closed-loop response matrices $\left(\sigma_{\mathrm{j}}\left[\mathrm{T}_{\mathrm{S}}(\mathrm{j} \omega)\right]\right.$, with $\left.\bar{y}(s)=T_{s}(s) \cdot \bar{y}_{c_{s}}(s)\right)$. Excellent matching was obtained for all these comparisons, indicating that the closed-loop performance and the desirable feedback properties of the integrated LQG/LTR compensator are retained in the partitioned sub-controllers. Example comparison results are presented after the sub-controller order reduction and simplification discussed in the following subsection.

\section{Sub-Controller Order Reduction and Simplification}

For ease of implementation, it is desirable to further reduce the order of the sub-controllers and simplify the structure by eliminating the insignificant feedbacks. Each of the sub-controllers, from eqns. (16) and (17), can be represented in the form

$$
\dot{\bar{x}}_{c_{i}}=A_{c_{i}} \bar{x}_{c_{i}}+B_{c_{i}}^{\prime} \bar{e}_{y_{i}}^{\prime} ; \quad \bar{u}_{i}=C_{c_{i}} x_{c_{i}}+D_{c_{i}}^{\prime} e_{y_{i}}^{\prime}
$$

with $\mathrm{e}_{\mathrm{y}_{\mathrm{i}}^{\prime}}^{\prime} \equiv \operatorname{col} .\left[\mathrm{e}_{\mathrm{y}_{\mathrm{i}}}, \overline{\mathrm{e}}_{\mathrm{y}_{\mathrm{j}}}\right]$, and corresponding definitions of $\mathrm{B}_{\mathrm{c}_{\mathrm{i}}}^{\prime}$ and $\mathrm{D}_{\mathrm{c}_{\mathrm{i}}}^{\prime}$. The model reduction technique based on internally-balanced realizations ${ }^{[22]}$ can then be used on a system in the above form to obtain reduced order sub-controllers. The internally-balanced realization approach consists of transforming the system into a set of states such that each state has the same controllability/observability index and, furthermore, the states are ordered in decreasing value of controllability/observability index. The reduced order system is then obtained by eliminating the states that are "less" controllable/observable. Note that in general, a frequency-weighted internally-balanced reduction technique ${ }^{[23]}$ has been shown to lead to a "better" lower order approximation for controller reduction. However, in the present design study, the frequency weighted technique is quite cumbersome to apply as the state-space realization of the frequency weighting, suggested in Ref. [23], will itself be of very high order. 
Using the internally-balanced realization approach, the order of the airframe controller was reduced from 5 to 2 and that of the engine controller from 8 to 7 . The system matrices for these reduced order sub-controllers, consistent with the definitions in (16) and (17) and corresponding to the input/output pairing of (20), are listed in the Appendix. From the data in the Appendix, we note that there is very little direct coupling from the output of one sub-controller into the output of other sub-controller, i.e. $W_{e a}$ and $\mathrm{W}_{\mathrm{ae}}$ are $\approx 0$, and also the engine control variable errors $\left(\mathrm{e}_{\mathrm{N}_{2} \mathrm{P}_{\mathrm{s}}}\right.$ and $\left.\mathrm{e}_{\mathrm{EPR}_{\mathrm{s}}}\right)$ do not significantly drive the states of the airframe sub-controller, i.e. last two columns of $\Gamma_{\mathrm{ae}}$ $\left(\Gamma_{\mathrm{ae}}(:, 2: 3)\right)$ are $\approx 0$. Therefore, the sub-controllers were simplified with $\mathrm{W}_{\mathrm{ae}}=0, \mathrm{~W}_{\mathrm{ea}}=0$, and $\Gamma_{\mathrm{ae}}(:, 2: 3)=0$. Note that the fact that such a simplification was possible in the present example indicates that the coupling between the airframe dynamics and the engine dynamics is not very strong. Such will not be the case in general for the STOVL aircraft being considered for the future.

The loop transfer matrix singular values $\left(\sigma_{\mathrm{i}}[\mathrm{GK}(\mathrm{j} \omega)]\right)$ with $\mathrm{K}(\mathrm{j} \omega)$ corresponding to the compensator obtained by assembling the reduced order and simplified sub-controllers are shown in Fig. 10. Comparing Fig. 10 to Fig. 4, we note that the loop shapes obtained with the LQG/LTR compensator are preserved in the compensator partitioning and simplification. The closed-loop response singular values $\left(\sigma_{\mathrm{i}}\left[\mathrm{T}_{\mathrm{s}}(\mathrm{j} \omega)\right]\right)$ with the LQG/LTR compensator and the assembled, simplified sub-controllers are compared in Fig. 11. Note that only the maximum and minimum singular values are shown in Fig. 11 to avoid cluttering the figure. From Fig. 11, we note that there is no noticeable change in closed-loop system performance on partitioning and simplifying the compensators.

The closed-loop system block diagram with the simplified sub-controllers is shown in Fig. 12. The representation in Fig. 12 is consistent with that in Fig. 7, i.e. the integrators augmented to the plant for compensator design and the input/output scaling matrices are incorporated in the airframe and engine sub-controllers. The blocks marked $\mathrm{P}_{(\cdot)}$, in Fig. 12, correspond to the command shaping filters and are discussed in the 
following section. Also, as shown in Fig. 12, the engine control variable commands ( $\mathrm{N}^{\mathrm{P}} \mathrm{Pel}$ and $\mathrm{EPR}_{\text {sel }}$ ) will be generated by engine scheduling control system. The discussion of the engine scheduling is beyond the scope of the research reported herein, as it requires knowledge of the nonlinear behavior of the propulsion system dynamics.

\section{Pre-Filter Design}

With a satisfactory feedback compensator obtained as above, the next step in the DMICS procedure is to design command shaping prefilters to obtain the desired response to airframe and engine command inputs. The linear quadratic regulator based prefilter synthesis procedure ${ }^{[7]}$ was used in the present study. As shown in Fig. 12, separate single-input single-output prefilters were designed for each controlled variable as decoupled responses to pilot and engine command inputs $\left(\delta_{\mathrm{st}}(\mathrm{in}\right.$.$) and \mathrm{V}_{\text {sel }}$, and $\mathrm{N}^{2} \mathrm{P}_{\text {sel }}$ and $\mathrm{EPR}_{\text {sel }}$ respectively) were desired, and the feedback compensator itself provides decoupled tracking of the commanded variables.

The desired controlled variable responses to pilot and engine command inputs are listed in Table 1 in transfer function form. In Table 1, the velocity response choice is such as to result in a well-damped response with minimal overshoot and a rapid settling time with a rise time $t_{r_{90}}=5$ secs, and the pitch rate response $\left(\frac{\mathrm{q}}{\delta_{\text {st }}}\right)$ selection is based on desired short period characteristics for Level I handling qualities ${ }^{[8]}$. The N2P and EPR response selections are based on the desired command tracking bandwidths. Note that the desired pitch variable response $\left(\frac{\mathrm{q} v}{\delta_{\mathrm{st}}}\right)$ can be obtained from the desired $\frac{\mathrm{q}}{\delta_{\mathrm{st}}}$ response using the definition $\mathrm{q}_{\mathrm{v}}=\mathrm{q}+0.1 \theta$.

The following steps were followed to obtain the command shaping prefilters that will give the desired response for each input/output pair :

1) The single-input single-output system from the commanded variable to the response variable with all the feedback loops closed was first obtained $\left(y_{i}=T_{i} y_{c_{i}}\right.$ 
where $\mathrm{y}_{\mathrm{i}}$ is one of $\mathrm{V}, \mathrm{q}_{\mathrm{v}}, \mathrm{N} 2 \mathrm{P}$ or EPR).

2) A reduced order approximation $\left(T_{r_{i}}\right)$ of $T_{i}$ was obtained using internally balanced realization. This step is important because the prefilter design procedure results in a prefilter of order greater than the "system" for which the prefilter is being designed.

3) The procedure of Ref. [7] was applied to the reduced order system $T_{r_{i}}$ to obtain the command shaping prefilter $\mathrm{P}_{\mathrm{i}}$ which will give the desired response.

4) The order of the prefilter was further reduced using the internally balanced realization approach.

The above process resulted in 4 th order prefilters for $\mathrm{V}, \mathrm{q}_{\mathrm{v}}$ and $\mathrm{N} 2 \mathrm{P}$, and a 1st order prefilter for EPR. The designed prefilters are listed in Table 2 in transfer function form. The Bode plots for the desired pitch rate response and that actually obtained with the complete designed control system are compared in Fig. 13. We note good agreement between the desired and actual response up to $5 \mathrm{rads} / \mathrm{sec}$ - well beyond the short-period frequency of $2.24 \mathrm{rads} / \mathrm{sec}$. The other three actual responses, although not shown here, were also in agreement with the desired responses for frequencies beyond the specified response bandwidths.

Finally, the frequency response Bode plots of pitch attitude and flight path response to pilot stick input, $\frac{\theta}{\delta_{\mathrm{st}}}$ and $\frac{\gamma}{\delta_{\mathrm{st}}}$ respectively, are shown in Fig. 14. From Fig. 14 we note that the flight path to pitch attitude relationship in the region of the short period frequency can be approximated by

$$
\left.\frac{\gamma}{\theta}\right|_{\mathrm{sp}} \approx \frac{0.5}{\mathrm{~s}+0.5}
$$

This is the response that was designed for by considering the angle of attack to flaps $(\alpha \rightarrow$ $\delta_{\mathrm{FL}}$ and $\left.\alpha \rightarrow \delta_{\mathrm{FT}}\right)$ loop closures prior to the feedback compensator design.

\section{Conclusions}

The major objective of this study was to gain extensive insight into the Linear 
Quadratic Gaussian/Loop Transfer Recovery (LQG/LTR) methodology based procedure for design of Integrated Flight/Propulsion Control (IFPC) laws. This methodology was one of two developed under the Air Force sponsored program on Design Methods for Integrated Control Systems (DMICS). Towards this objective, an example of an integrated flight/propulsion control system design, mainly based on the aforementioned DMICS study, was presented in this paper. The control system design was performed for the piloted longitudinal landing task of a modern, statically unstable, fighter aircraft powered by a two spool turbofan engine and equipped with a $2 \mathrm{D}$ thrust vectoring nozzle. As a result of this study, the following conclusions can be drawn regarding the strengths and weaknesses of the LQG/LTR based DMICS methodology :

(1) The major strength of the methodology lies in its ability to address design issues such as stability robustness and trade-off between performance and allowable control power directly in the synthesis procedure. The procedure for the design of the feedback compensator and command shaping is quite straightforward and can be accomplished with available control design software.

(2) The major drawback of the methodology is that it results in a single high-order, integrated feedback compensator. Although such an integrated compensator is intuitively appealing in that it will lead to "optimum" performance, it is unacceptable because of the difficulty of implementation as well as the desire to physically separate the flight and propulsion controllers.

(3) The methodology is mainly geared towards synthesizing command tracking control laws and so one of its weaknesses lies in its inability to address the issue of plant augmentation. In this example study, classical single-input single-output control law design techniques had to be used to synthesize the desired flight path augmentation prior to the application of the DMICS methodology.

(4) The methodology makes extensive use of singular values for synthesis as well as analysis. As is well known, and was also shown in this example study, the singular 
value based robustness analysis tends to be highly conservative. It was also shown that because of the scaling (normalization) used in the control law synthesis procedure, the LQG/LTR procedure guarantees the stability robustness properties at a point in the loop which is internal to the compensator as it will be implemented. This point is not the physical interface between the actual plant and the implementation compensator where the uncertainties will actually occur. Reducing the conservativeness of singular value stability robustness analysis and resolving the effect of scaling are issues which warrant further investigation.

To overcome the major drawback of this DMICS methodology, mainly that of one high order integrated feedback compensator (see (2) above), a technique was presented in this paper for partitioning the integrated compensator into the desired separate sub-controllers for the airframe and the engine. The suggested compensator partitioning approach was demonstrated by application to the example study, and led to much simplified sub-controllers without any significant loss in performance and stability robustness as compared to that obtained with the full order integrated compensator. The compensator partitioning approach, however, clearly needs to be validated for a system exhibiting higher degree of coupling between the sub-system dynamics than was the case in the present study.

\section{Appendix}

\section{Vehicle System Matrices:}

$$
\mathrm{A}_{\mathrm{p}}=\left[\begin{array}{cccccc}
-5.893 \mathrm{e}-02 & 1.067 \mathrm{e}-01 & -3.860 \mathrm{e}+01 & -3.184 \mathrm{e}+01 & 1.410 \mathrm{e}-02 & 3.144 \mathrm{e}-04 \\
-2.659 \mathrm{e}-01 & -2.665 \mathrm{e}-01 & 1.948 \mathrm{e}+02 & -4.599 \mathrm{e}+00 & 5.196 \mathrm{e}-04 & -1.578 \mathrm{e}-05 \\
-1.541 \mathrm{e}-03 & 7.806 \mathrm{e}-03 & -1.949 \mathrm{e}-01 & -4.818 \mathrm{e}-04 & 2.564 \mathrm{e}-05 & 9.463 \mathrm{e}-07 \\
0 & 0 & 1.0 & 0 & 0 & 0 \\
1.427 \mathrm{e}-01 & -9.898 \mathrm{e}-01 & 0 & 2.006 \mathrm{e}+02 & 0 & 0 \\
7.782 \mathrm{e}-01 & 1.542 \mathrm{e}-01 & 0 & 0 & -8.485 \mathrm{e}-02 & -4.191 \mathrm{e}+00 \\
1.518 \mathrm{e}-01 & 3.008 \mathrm{e}-02 & 0 & 0 & -1.655 \mathrm{e}-02 & 4.263 \mathrm{e}-01 \\
7.934 \mathrm{e}-01 & 1.572 \mathrm{e}-01 & 0 & 0 & -3.502 \mathrm{e}-01 & 2.295 \mathrm{e}-01 \\
-1.005 \mathrm{e}-01 & -1.992 \mathrm{e}-02 & 0 & 0 & 1.096 \mathrm{e}-02 & 3.740 \mathrm{e}-02
\end{array}\right.
$$




$$
\begin{aligned}
& 2.599 \mathrm{e}-04 \quad 3.819 \mathrm{e}-02 \quad 2.251 \mathrm{e}-03 \\
& -2.106 \mathrm{e}-06 \quad 1.826 \mathrm{e}-04-2.957 \mathrm{e}-06 \\
& 3.744 \mathrm{e}-07 \quad 3.668 \mathrm{e}-05 \quad 2.673 \mathrm{e}-06 \\
& \begin{array}{lll}
0 & 0 & 0
\end{array} \\
& \begin{array}{lll}
0 & 0 & 0
\end{array} \\
& 6.022 \mathrm{e}+00-3.434 \mathrm{e}+02 \quad 1.160 \mathrm{e}+01 \\
& -5.707 \mathrm{e}+00 \quad 2.716 \mathrm{e}+01 \quad 1.040 \mathrm{e}+01 \\
& 1.155 \mathrm{e}-01-9.024 \mathrm{e}+01 \quad 8.476 \mathrm{e}-01 \\
& -1.036 \mathrm{e}-01-7.954 \mathrm{e}+00-1.068 \mathrm{e}+00 \\
& \mathrm{~B}_{\mathrm{p}}=\left[\begin{array}{cccccc}
3.468 \mathrm{e}-02 & -4.960 \mathrm{e}-02 & 3.436 \mathrm{e}-05 & -2.055 \mathrm{e}-01 & 6.912 \mathrm{e}-02 & -4.183 \mathrm{e}-04 \\
6.925 \mathrm{e}-02 & -1.455 \mathrm{e}-01 & 1.234 \mathrm{e}-08 & -2.936 \mathrm{e}-04 & 7.104 \mathrm{e}-05 & -5.452 \mathrm{e}-01 \\
-8.100 \mathrm{e}-03 & 7.132 \mathrm{e}-04 & 5.507 \mathrm{e}-08 & 1.068 \mathrm{e}-04 & -8.383 \mathrm{e}-05 & -7.973 \mathrm{e}-02 \\
0 & 0 & 0 & 0 & 0 & 0 \\
0 & 0 & 0 & 0 & 0 & 0 \\
0 & 0 & 1.469 \mathrm{e}-01 & 0 & 0 & 0 \\
0 & 0 & 5.366 \mathrm{e}-02 & 0 & 0 & 0 \\
0 & 0 & 1.813 \mathrm{e}-02-4.302 \mathrm{e}+01 & -2.583 \mathrm{e}+01 & 0 \\
0 & 0 & 1.643 \mathrm{e}-01 & 0 & 0 & 0
\end{array}\right] \\
& \mathrm{C}_{\alpha}=\left[\begin{array}{llllllllll}
-5.888 \mathrm{e}-02 & 2.796 \mathrm{e}-01 & 0 & 0 & 0 & 0 & 0 & 0 & 0
\end{array}\right] \\
& \mathrm{C}_{\mathrm{p}}=\left[\begin{array}{ccccccccc}
9.797 \mathrm{e}-01 & 1.941 \mathrm{e}-01 & 0 & 0 & 0 & 0 & 0 & 0 & 0 \\
0 & 0 & 5.730 \mathrm{e}+01 & 5.730 \mathrm{e}+00 & 0 & 0 & 0 & 0 & 0 \\
0 & 0 & 0 & 0 & 0 & 8.723 \mathrm{e}-03 & 0 & 0 & 0 \\
0 & 0 & 0 & 0 & 0 & 0 & 0 & 6.803 \mathrm{e}-02 & 0
\end{array}\right]
\end{aligned}
$$

Scaling Matrices:

$$
\begin{gathered}
S_{u}=\operatorname{diag}[2.0 \mathrm{e}-04,0.02,0.01,0.1] \\
S_{y}=\operatorname{diag}[0.05,0.3,0.2,3.0]
\end{gathered}
$$

Reduced-Order Sub-Controller matrices:

$$
\begin{aligned}
& A_{c_{a}}=\left[\begin{array}{r}
-5.873 \mathrm{e}+01-4.146 \mathrm{e}+01 \\
4.146 \mathrm{e}+01-7.861 \mathrm{e}-02
\end{array}\right] ; \mathrm{B}_{\mathrm{c}_{\mathrm{a}}}=\left[\begin{array}{r}
-2.684 \mathrm{e}+01 \\
9.322 \mathrm{e}-01
\end{array}\right] \\
& \mathrm{C}_{\mathrm{c}_{\mathrm{a}}}=[2.684 \mathrm{e}+019.323 \mathrm{e}-01]
\end{aligned}
$$

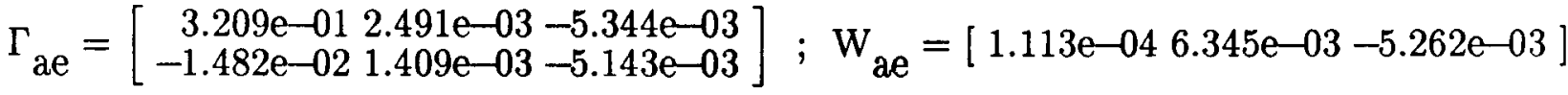

$$
\begin{aligned}
& \mathrm{A}_{\mathrm{c}_{\mathrm{e}}}=\left[\begin{array}{rrr}
-1.671 \mathrm{e}-01-1.907 \mathrm{e}+01-1.526 \mathrm{e}-01 & 8.728 \mathrm{e}-04-1.040 \mathrm{e}+00 \\
1.737 \mathrm{e}+01-2.023 \mathrm{e}+01-1.434 \mathrm{e}-01 & -1.579 \mathrm{e}-02-1.064 \mathrm{e}+01 \\
9.982 \mathrm{e}-02-4.347 \mathrm{e}-02-1.213 \mathrm{e}+01 & 8.596 \mathrm{e}+00-1.698 \mathrm{e}-01 \\
-6.165 \mathrm{e}-03-9.159 \mathrm{e}-02-8.559 \mathrm{e}+00 & -1.856 \mathrm{e}-02-2.981 \mathrm{e}-02 \\
1.170 \mathrm{e}+00-1.067 \mathrm{e}+01-2.406 \mathrm{e}-01 & -1.642 \mathrm{e}-02-1.928 \mathrm{e}+01 \\
5.297 \mathrm{e}+00-1.411 \mathrm{e}+01-1.630 \mathrm{e}+00 & 1.159 \mathrm{e}-01-1.032 \mathrm{e}+02 \\
8.426 \mathrm{e}-01-5.655 \mathrm{e}+00-3.689 \mathrm{e}-01-4.437 \mathrm{e}-03-3.562 \mathrm{e}+01
\end{array}\right.
\end{aligned}
$$




$$
\begin{aligned}
& 4.518 \mathrm{e}-01-2.837 \mathrm{e}-01 \\
& 1.036 \mathrm{e}+00 \quad 7.068 \mathrm{e}-02 \\
& 6.662 \mathrm{e}-03 \quad 9.724 \mathrm{e}-02 \\
& -4.037 \mathrm{e}-02 \quad 1.264 \mathrm{e}-03 \\
& -1.894 \mathrm{e}+01 \quad 2.991 \mathrm{e}+01 \\
& -3.599 \mathrm{e}+02 \quad 2.509 \mathrm{e}+02 \\
& -2.467 \mathrm{e}+02-2.091 \mathrm{e}+01 \\
& \mathrm{~B}_{\mathrm{C}_{\mathrm{e}}}=\left[\begin{array}{rrr}
-1.948 \mathrm{e}-02 & -1.872 \mathrm{e}-02 & 1.835 \mathrm{e}+00 \\
2.746 \mathrm{e}-01 & 1.916 \mathrm{e}+01 & -7.368 \mathrm{e}-01 \\
-1.128 \mathrm{e}+01 & 2.138 \mathrm{e}-01 & -2.278 \mathrm{e}-01 \\
-3.723 \mathrm{e}-01 & 5.392 \mathrm{e}-02 & 2.792 \mathrm{e}-02 \\
8.107 \mathrm{e}-02 & 5.754 \mathrm{e}+00 & -5.444 \mathrm{e}+00 \\
-6.793 \mathrm{e}-02 & 5.501 \mathrm{e}+00 & -2.934 \mathrm{e}+01 \\
-2.886 \mathrm{e}-02 & 2.508 \mathrm{e}+00 & -4.505 \mathrm{e}+00
\end{array}\right] ; \Gamma_{\text {ea }}=\left[\begin{array}{r}
2.858 \mathrm{e}-03 \\
-1.406 \mathrm{e}-02 \\
9.420 \mathrm{e}-01 \\
1.849 \mathrm{e}-01 \\
-8.075 \mathrm{e}-03 \\
-2.003 \mathrm{e}-02 \\
4.307 \mathrm{e}-04
\end{array}\right] \\
& \mathrm{C}_{\mathrm{C}_{\mathrm{e}}}=\left[\begin{array}{rrrrr}
1.812 \mathrm{e}+00 & 1.914 \mathrm{e}+01 & 1.991 \mathrm{e}-01 & 2.549 \mathrm{e}-02 & 5.612 \mathrm{e}+00 \\
-1.366 \mathrm{e}-01 & 6.072 \mathrm{e}-01 & 8.751 \mathrm{e}+00 & -3.204 \mathrm{e}-01 & 3.561 \mathrm{e}+00 \\
-2.567 \mathrm{e}-01 & 1.056 \mathrm{e}+00 & -7.188 \mathrm{e}+00 & 2.705 \mathrm{e}-01 & 4.311 \mathrm{e}+00
\end{array}\right. \\
& \left.\begin{array}{rr}
-1.449 \mathrm{e}+00 & 4.761 \mathrm{e}-01 \\
1.908 \mathrm{e}+01 & -3.284 \mathrm{e}+00 \\
2.292 \mathrm{e}+01 & -3.946 \mathrm{e}+00
\end{array}\right] ; \mathrm{W}_{\text {ea }}=\left[\begin{array}{r}
-2.408 \mathrm{e}-04 \\
-1.189 \mathrm{e}-02 \\
9.894 \mathrm{e}-03
\end{array}\right]
\end{aligned}
$$

Sub-Controller Simplification:

$$
\Gamma_{\mathrm{ae}}(:, 2: 3)=0 \quad ; \quad \mathrm{W}_{\mathrm{ae}}=0 \quad ; \quad \mathrm{W}_{\mathrm{ea}}=0 .
$$

\section{Acknowledgement}

The authors would like to thank Mr. Kevin Madden and Dr. P.D. Shaw, Flight Control Research Dept., Northrop Corp., Hawthorne, CA., for having provided the linearized aircraft models used in this study.

\section{References}

[1] Smith, K.L., "Design Methods for Integrated Control Systems," AFWAL-TR-86-2103, Wright Patterson AFB, Dayton, OH., December 1986.

[2] Shaw, P.D., Rock, S.M., and Fisk, W.S., "Design Methods for Integrated Control Systems," AFWAL-TR-88-2061, Aero Propulsion Laboratories, Wright Patterson AFB, Dayton OH, June 1988.

[3] Mihaloew, J., "Flight Propulsion Control Integration for V/STOL Aircraft," NASA TM-100226, Dec. 1987.

[4] Smith, K.L., Kerr, W.B., Hartmann, G.L., and Skira, C., "Aircraft Control Integration - Methodology and Performance Impact," AIAA Paper 85-1424, Presented at the AIAA/SAE/ASME/ASEE 21st Joint Propulsion Conference, 
Monterey, CA., July 1985.

[5] Stein, G., and Athans, M., "The LQG-LTR Procedure for Multivariable Feedback Control Design," Report LIDS-R-1384, Massachusetts Institute of Technology, Cambridge, MA., May 1984.

[6] Athans, M., "A Tutorial on the LQG/LTR Method," LIDS-P-1542, Massachusetts Institute of Technology, Cambridge, MA., March 1986.

[7] Lehtomaki, N.A., Stein, G., and Wall, J.E., "Multivariable Prefilter Design for Command Shaping," AIAA Paper 84-1829, Guidance, Navigation and Control Conference, Seattle, WA., August 1984.

[8] "Military Specification - Flying Qualities of Piloted Airplanes," MIL-F-8785C, USAF, Wright Patterson AFB, OH., Nov. 1980.

[9] McRuer, D.T., Ashkenas, I., and Graham, D., "Aircraft Dynamics and Automatic Control," Princeton University Press, 1973.

[10] Garg, S., "Model-Based Analysis and Cooperative Synthesis of Control and Display Augmentation for Piloted Flight Vehicles," Ph.D. Thesis, School of Aeronautics and Astronautics, Purdue University, West Lafayette, IN., May 1988.

[11] Garg, S., "Turbofan Engine Control System Design Using the LQG/LTR methodology," 1989 American Control Conference, Pittsburgh, PA., June 1989.

[12] Kwakernaak, H., and Sivan, R., "Linear Optimal Control Systems," Wiley Interscience, 1972.

[13] Athans, M., Kapassouris, P., Kappos, E., and Spang III, H.A., "Linear-Quadratic Gaussian with Loop-Transfer Recovery Methodology for the F-100 Engine," Journal of Guidance, Control and Dynamics, Vol. 9, Jan.-Feb. 1986, pp. 45-52.

[14] Ridgley, B.D., Banda, S.S., McQuade, T.E., and Lynch, P.J., "Linear-Quadratic Gaussian with Loop-Transfer Recovery Methodology for an Unmanned Aircraft," Journal of Guidance, Control and Dynamics, Vol. 10, Jan.-Feb. 1987, pp. 82-89.

[15] Lehtomaki, N.A., "Practical Robustness Measures in Multi-variable Control System Analysis," Ph.D. Thesis (LIDS-TH-1093), Massachusetts Institute of Technology, Cambridge, May 1981.

[16] Lehtomaki, N.A., sandell Jr., N.R., and Athans, M., "Robustness Results in LQG-Based Multivariable Control Design," IEEE Transactions on Automatic Control, Vol. AC-26, Feb. 1981, pp. 75-92.

[17] Ogata, K., "Modern Control Engineering", Prentice Hall, Inc., 1970.

[18] Safonov, M.G., and Doyle, J.C., "Minimizing Conservativeness of Robustness Singular Values," S.G. Tzefestas (ed.), ul Multivariable Control, D. Reidel Publishing Company, Dordrecht, Holland, 1984, pp. 197-207.

[19] Apkarian, P.R., "Structured Stability Robustness Improvement by Eigenspace Assignment Techniques: A Hybrid Methodology," Journal of Guidance, Control and Dynamics, Vol. 12, No. 2, March-April 1989, pp. 162-168. 
[20] Osborne, E.E., "On Pre-Conditioning of Matrices," Journal of the Association for Computing Machinery, Vol. 7, 1960, pp. 338-345.

[21] Noble, B., and Daniel, J., "Applied Linear Algebra," Prentice-Hall, Inc., 1977.

[22] Moore, B.C., "Principal Component Analysis in Linear Systems: Controllability, Observability, and Model Reduction," IEEE Trans. on Automatic Control, Vol. AC-26, Feb. 1981.

[23] Enns, D.F., "Model Reduction for Control System Design," Ph.D. Thesis, Department of Aeronautics and Astronautics, Stanford University, Stanford, CA., June 1984. 
Table 1. Desired Response Transfer Functions

$$
\begin{aligned}
& \text { Notation : }\left\{\mathrm{K}(1 / \tau)\left[\zeta ; \omega_{\mathrm{n}}\right] \equiv \mathrm{K}(\mathrm{s}+1 / \tau)\left(\mathrm{s}^{2}+2 \zeta \omega_{\mathrm{n}} \mathrm{s}+\omega_{\mathrm{n}}^{2}\right)\right\} \\
& \frac{\mathrm{V}}{\mathrm{V}_{\text {s el }}}=\frac{0.04(3.13)}{[0.89 ; 0.36]} ; \frac{\mathrm{q}}{\delta_{\mathrm{st}}}=\frac{35.12(0.5)}{[0.89 ; 2.24]} \\
& \frac{\mathrm{N} 2 \mathrm{P}}{\mathrm{N}_{2} \mathrm{P}_{\text {s el }}}=\frac{5.0}{(5.0)} ; \frac{\mathrm{EPR}}{\mathrm{EPR}_{\text {s el }}}=\frac{10.0}{(10.0)}
\end{aligned}
$$

Table 2. Design Prefilter Transfer Functions

$$
\begin{gathered}
\text { Notation : }\left\{\mathrm{K}(1 / \tau)\left[\zeta ; \omega_{\mathrm{n}}\right]=\mathrm{K}(\mathrm{s}+1 / \tau)\left(\mathrm{s}^{2}+2 \zeta \omega_{\mathrm{n}} \mathrm{s}+\omega_{\mathrm{n}}^{2}\right)\right\} \\
\frac{\mathrm{V}_{\mathrm{c}}}{\mathrm{V}_{\mathrm{s} \text { el }}}=\frac{0.013[0.67 ; 1.37](5.20)(830.21)}{[0.89 ; 0.31][0.56 ; 32.42]} \\
\frac{\mathrm{q}_{\mathrm{c}}}{\delta_{\mathrm{st}}}=\frac{3.60(0.10)(0.51)(1.22)(5.61)}{(0)(0.67)[0.89 ; 2.24]} \\
\frac{\mathrm{N}_{\mathrm{C}} \mathrm{C}_{\mathrm{c}}}{{\mathrm{N} 2 \mathrm{P}_{\mathrm{sel}}}_{1}}=\frac{486.45[0.53 ; 4.05](66.93)}{(5.0)(13.03)[0.71 ; 90.50]} ; \frac{\mathrm{EPR}_{\mathrm{c}}}{\mathrm{EPR}_{\mathrm{sel}}}=\frac{1.30(7.67)}{(10.0)}
\end{gathered}
$$




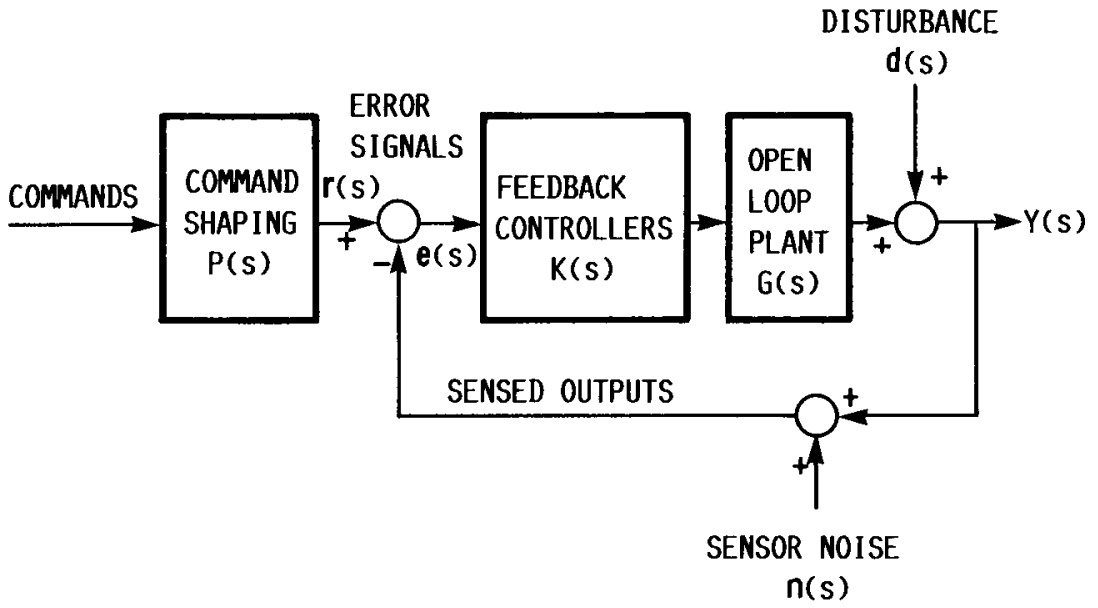

FIGURE 1. - BLOCK DIAGRAM OF FEEDBACK CONTROL WITH COMMAND SHAPING.

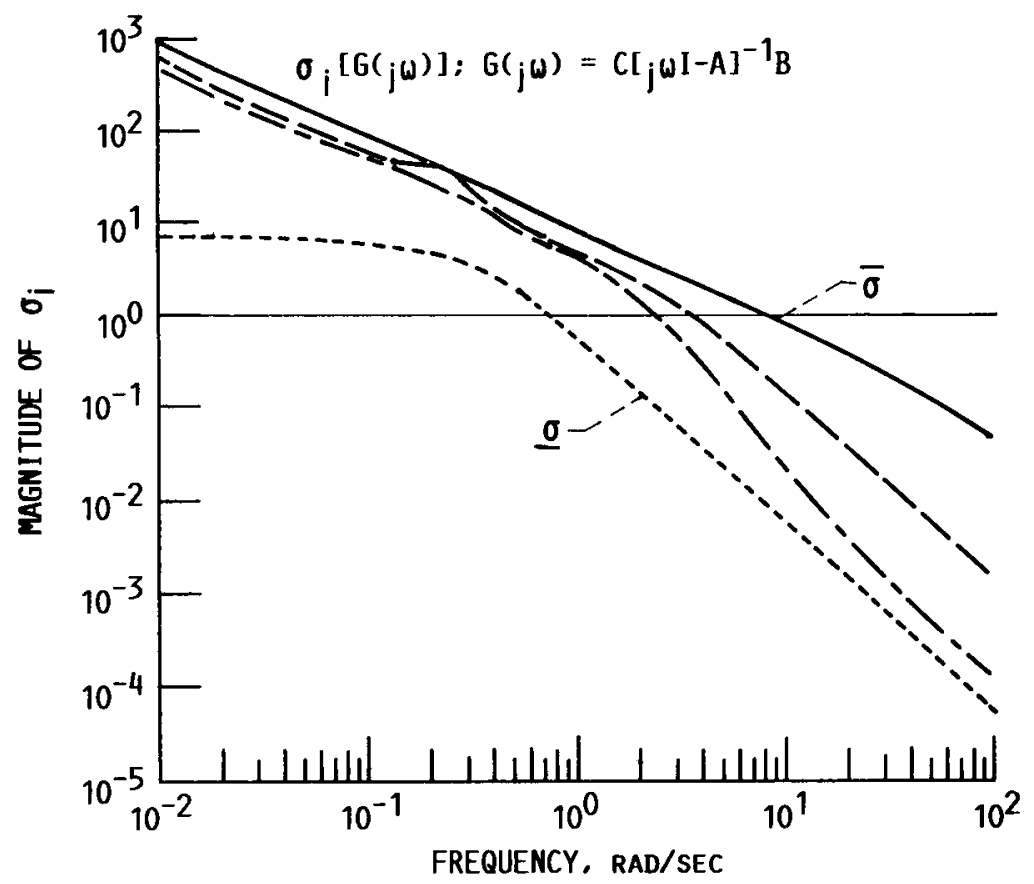

FIGURE 2. - SINGULAR VALUES OF SCALED, AUGMENTED PLANT $\left(\sigma_{i}[G(j \omega)]\right)$. 

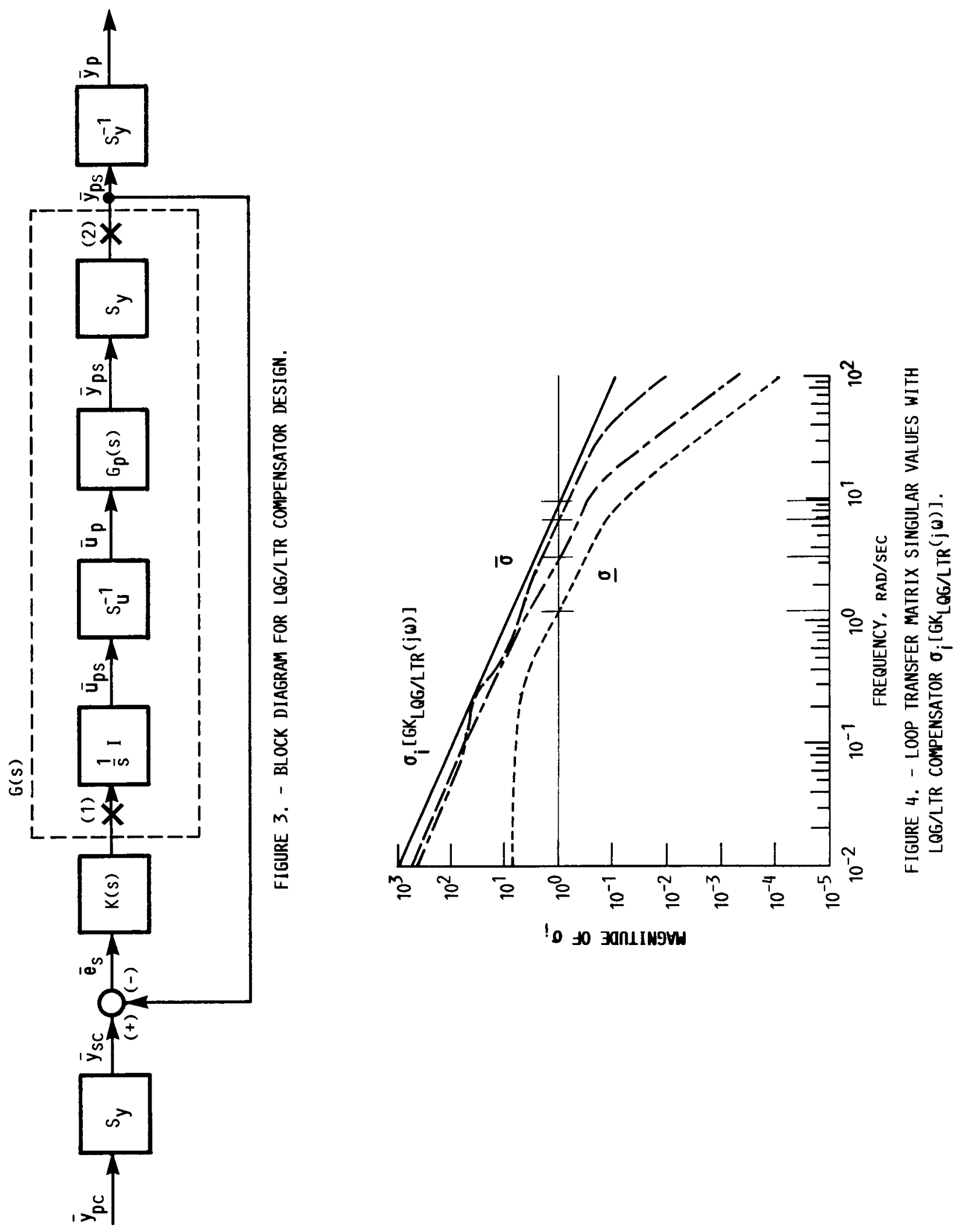

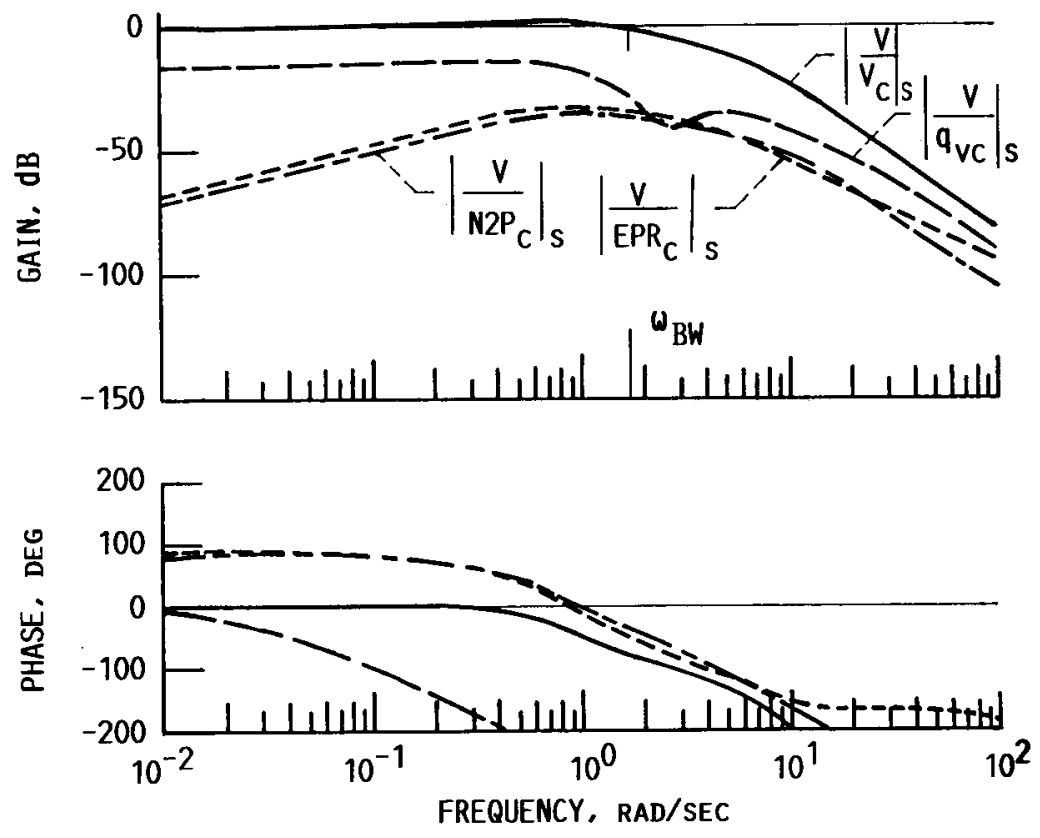

FIGURE 5. - CLOSED-LOOP BODE PLOTS OF AIRCRAFT VELOCITY, $V$, RESPONSE TO COMMAND INPUTS $\left(v_{c}, q_{v c},{ }^{N 2 P} P_{c}\right.$ AND EPR $_{C}$ ) - SCALED SYSTEM.

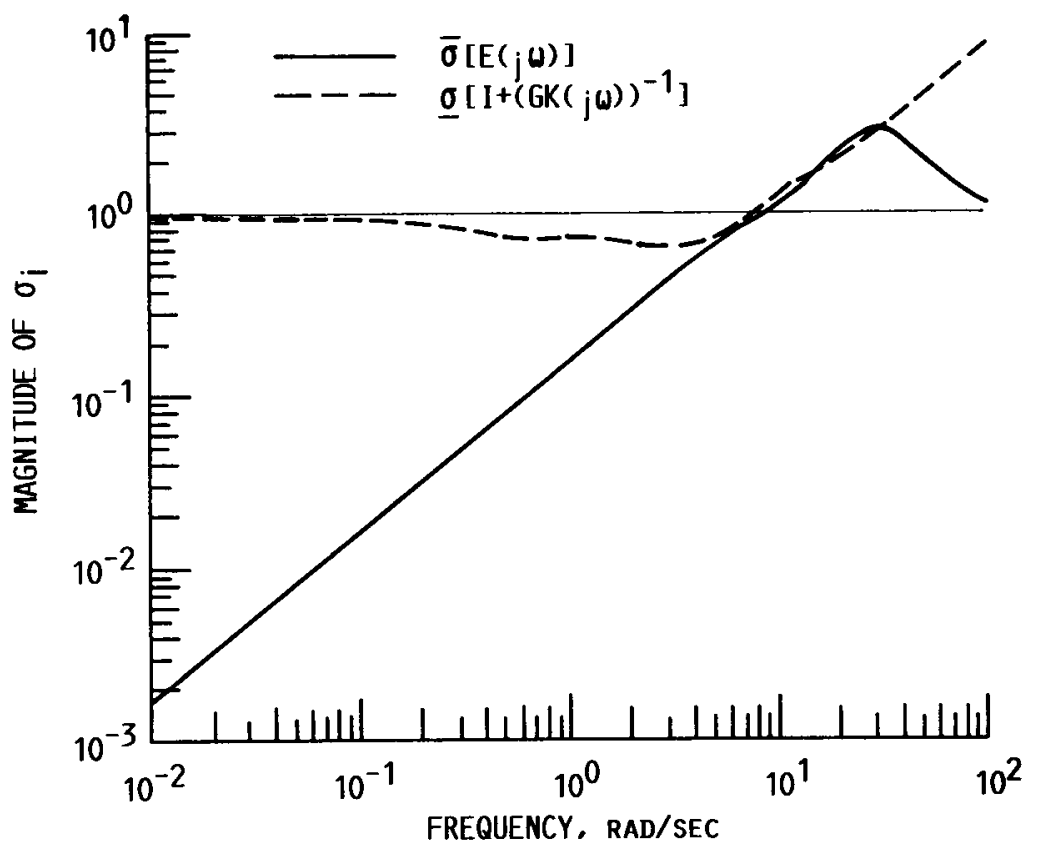

FIGURE 6. - STABILITY ROBUSTNESS CHECK USING SINGULAR VALUES. 

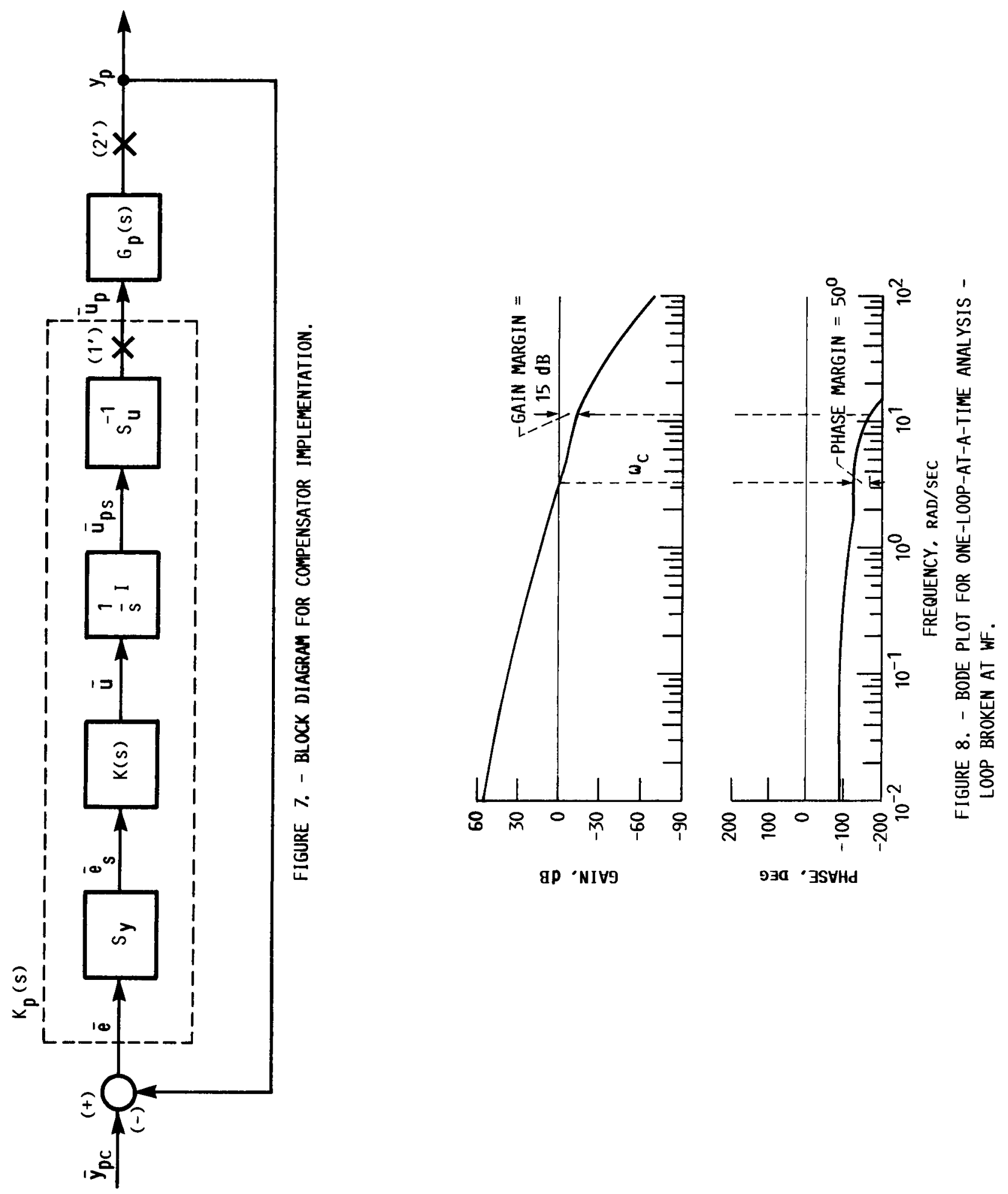


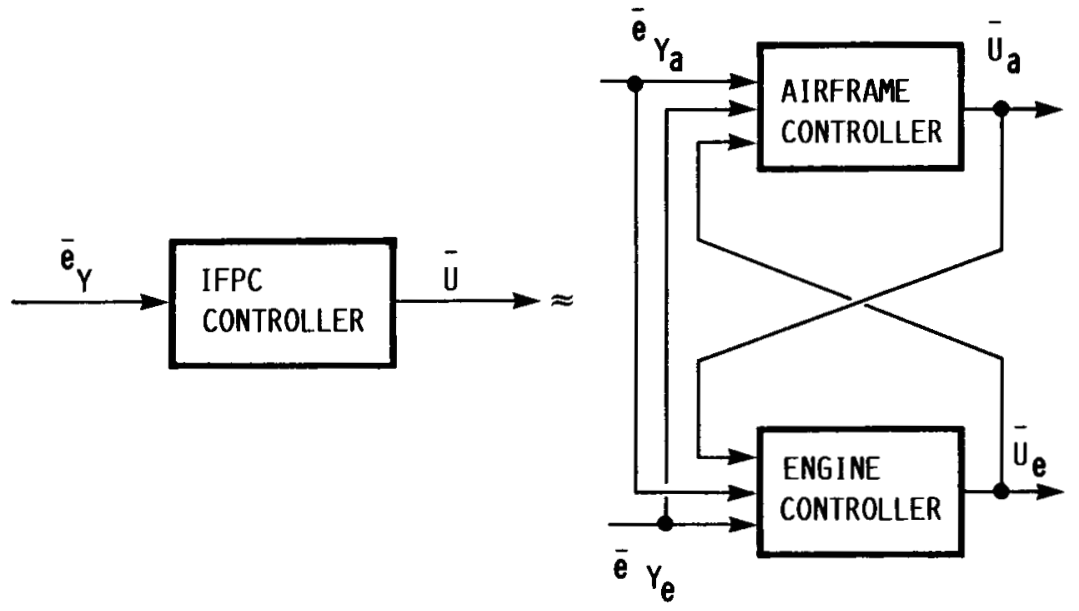

(a) CENTRALIZED COMPENSATOR. (b) PARTITIONED SUB-CONTROLLERS.

FIGURE 9. - BLOCK DIAGRAM FOR COMPENSATOR PARTITIONING.

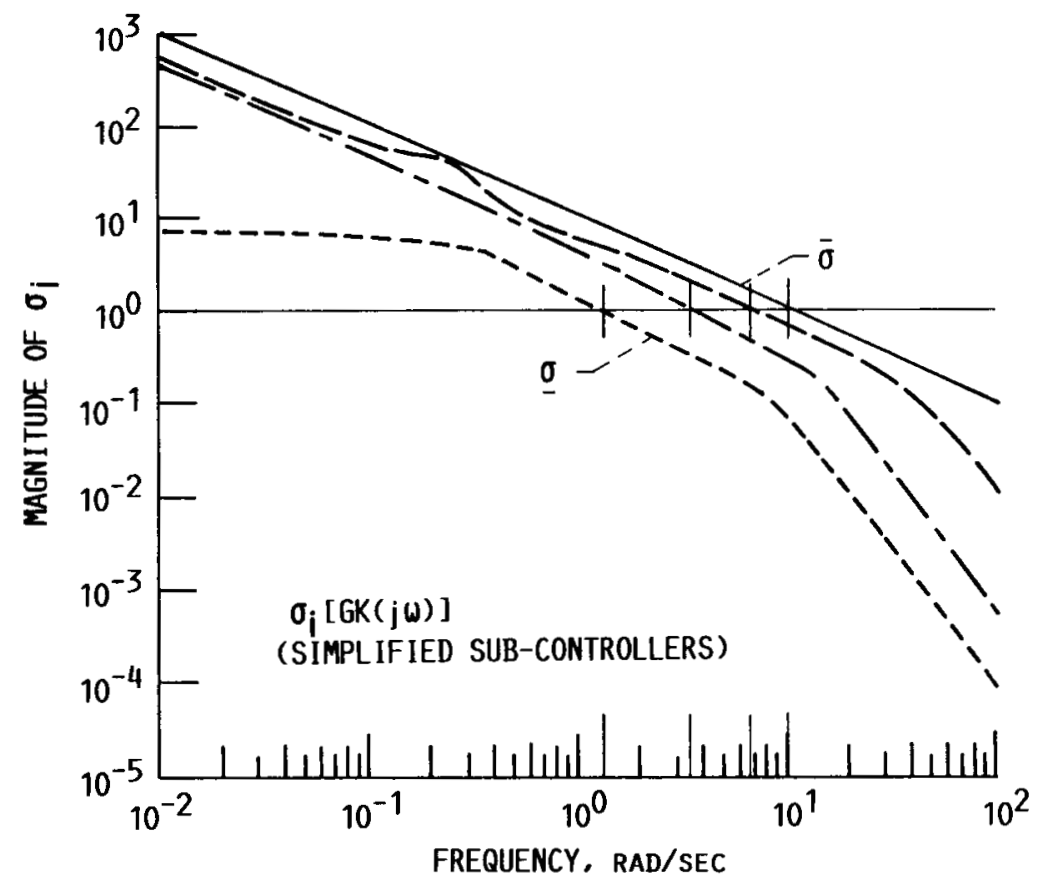

FIGURE 10. - LOOP TRANSFER MATRIX SINGULAR VALUES $\left(\sigma_{j}[G K(j \omega)]\right)$ WITH PARTITIONED, REDUCED AND SIMPLIFIED SUB-CONTROLLERS. 


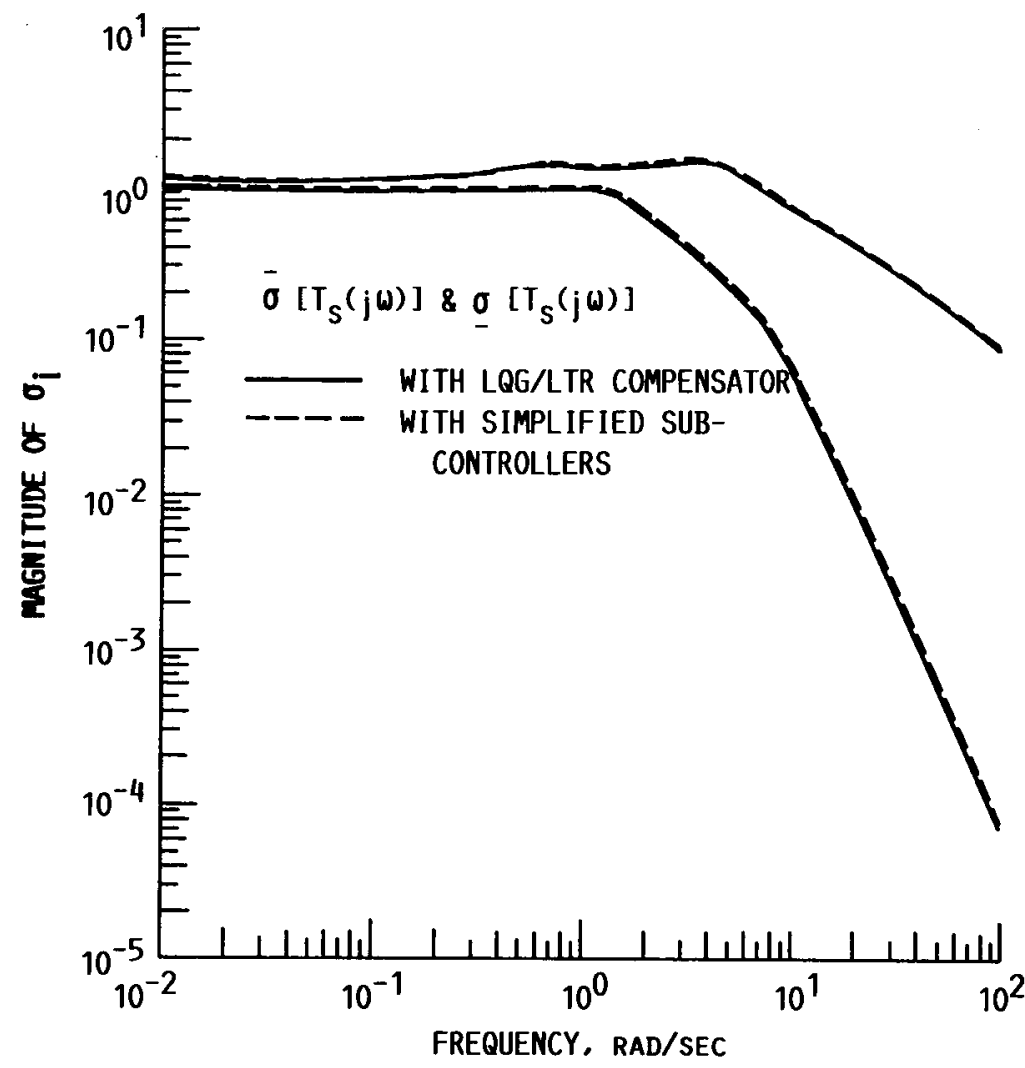

FIGURE 11. - CLOSED LOOP SYSTEM RESPONSE COMPARISON WITH LQG/LTR COMPENSATOR AND WITH PARTITIONED, REDUCED AND SIMPLIFIED SUB-CONTROLLERS. 


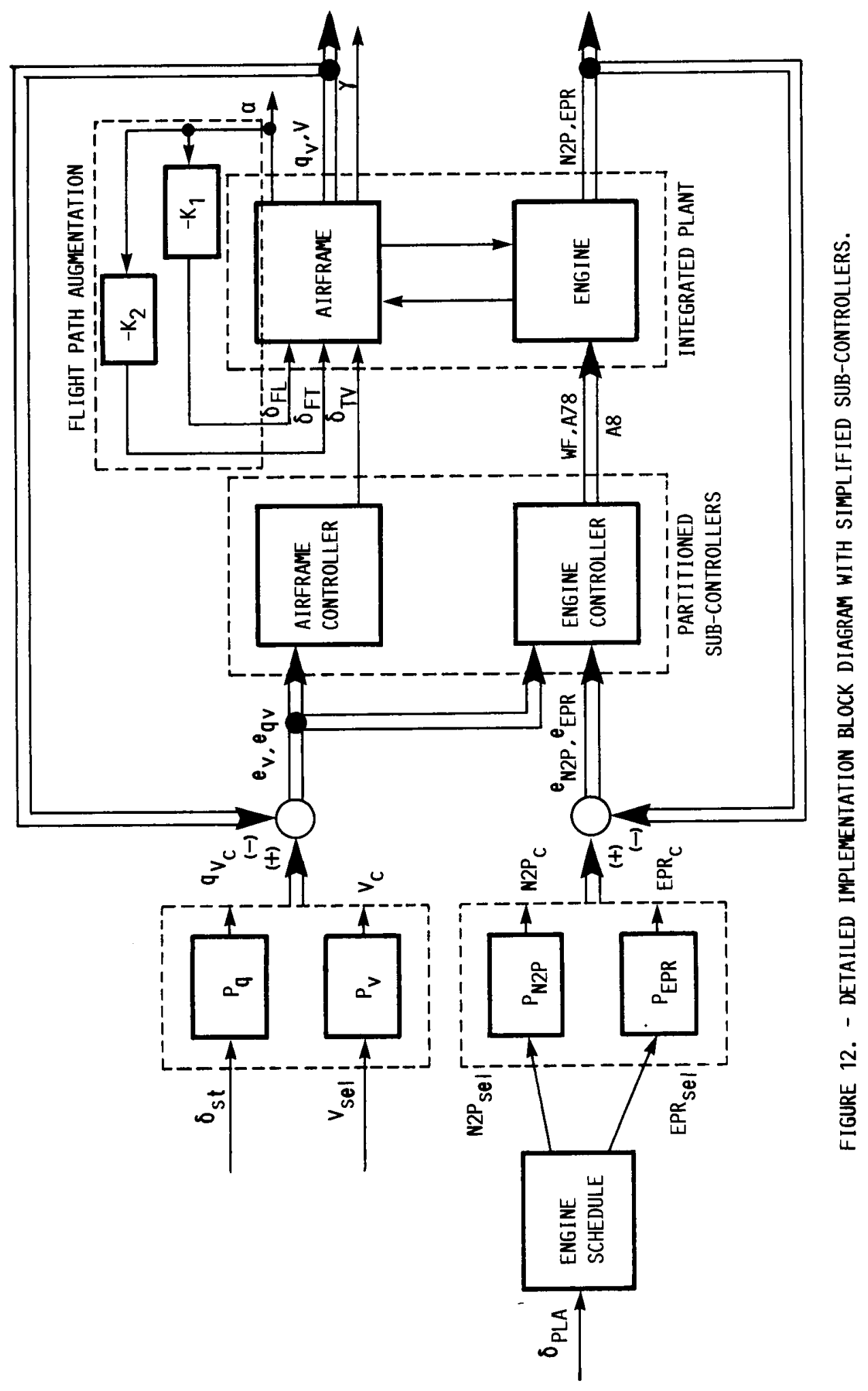



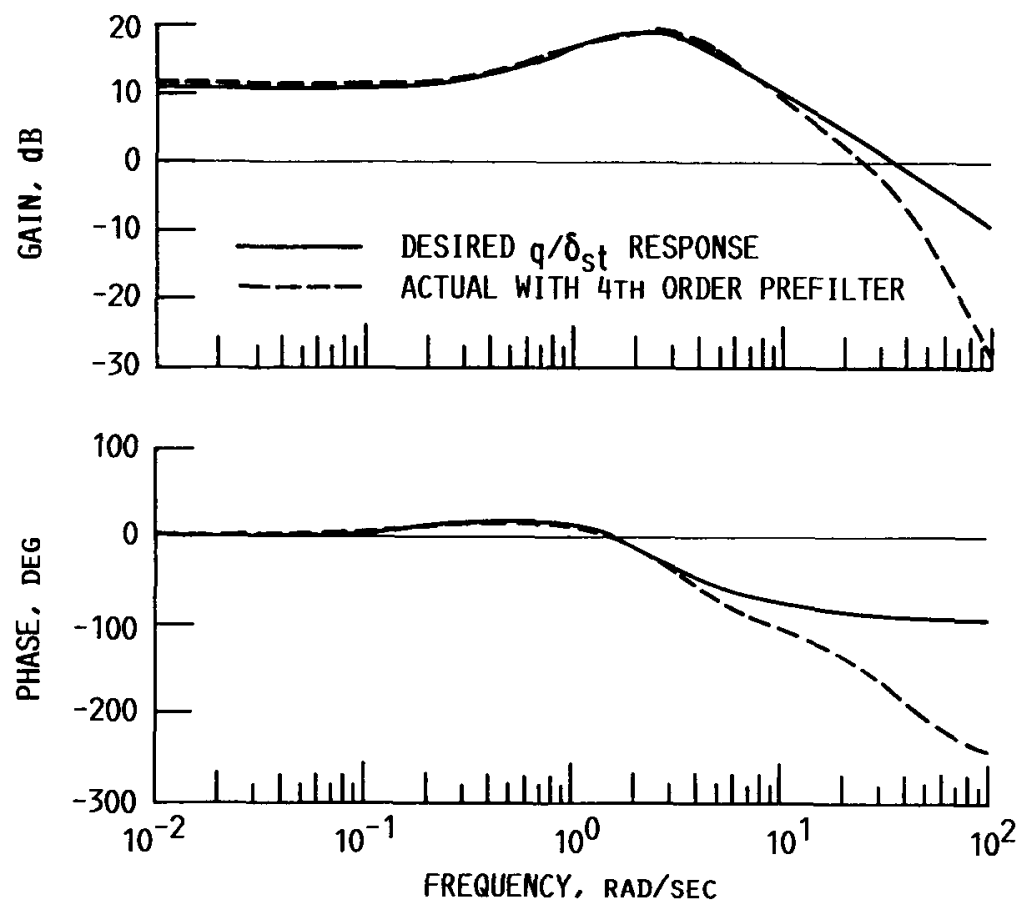

FIGURE 13. - BODE PLOTS OF DESIRED AND ACTUAL PITCH RATE RESPONSE TO PILOT STICK INPUT $\left(q / \delta_{\text {St }}\right)$.
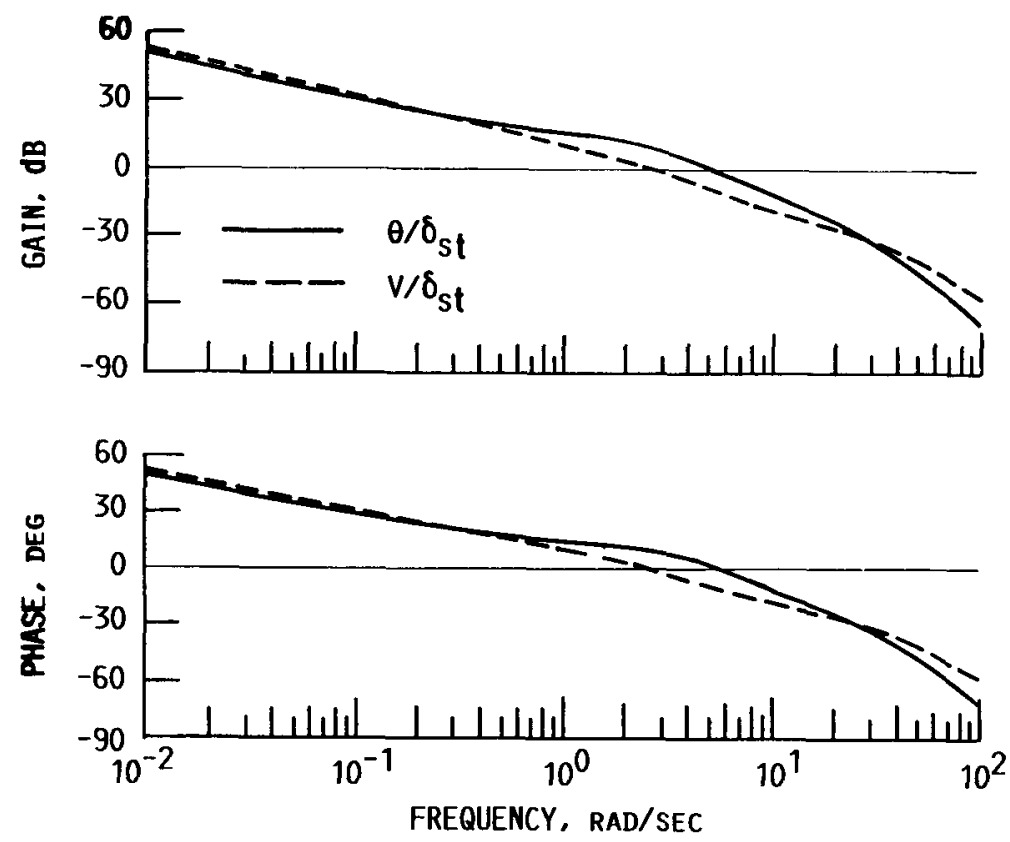

FIGURE 14. - BODE PLOTS OF PITCH ATTITUDE AND FLIGHT PATH ANGLE RESPONSE TO PILOT STICK INPUT $\left(\theta / \delta_{\text {st }}\right.$ AND $y / \delta_{s t}$. 


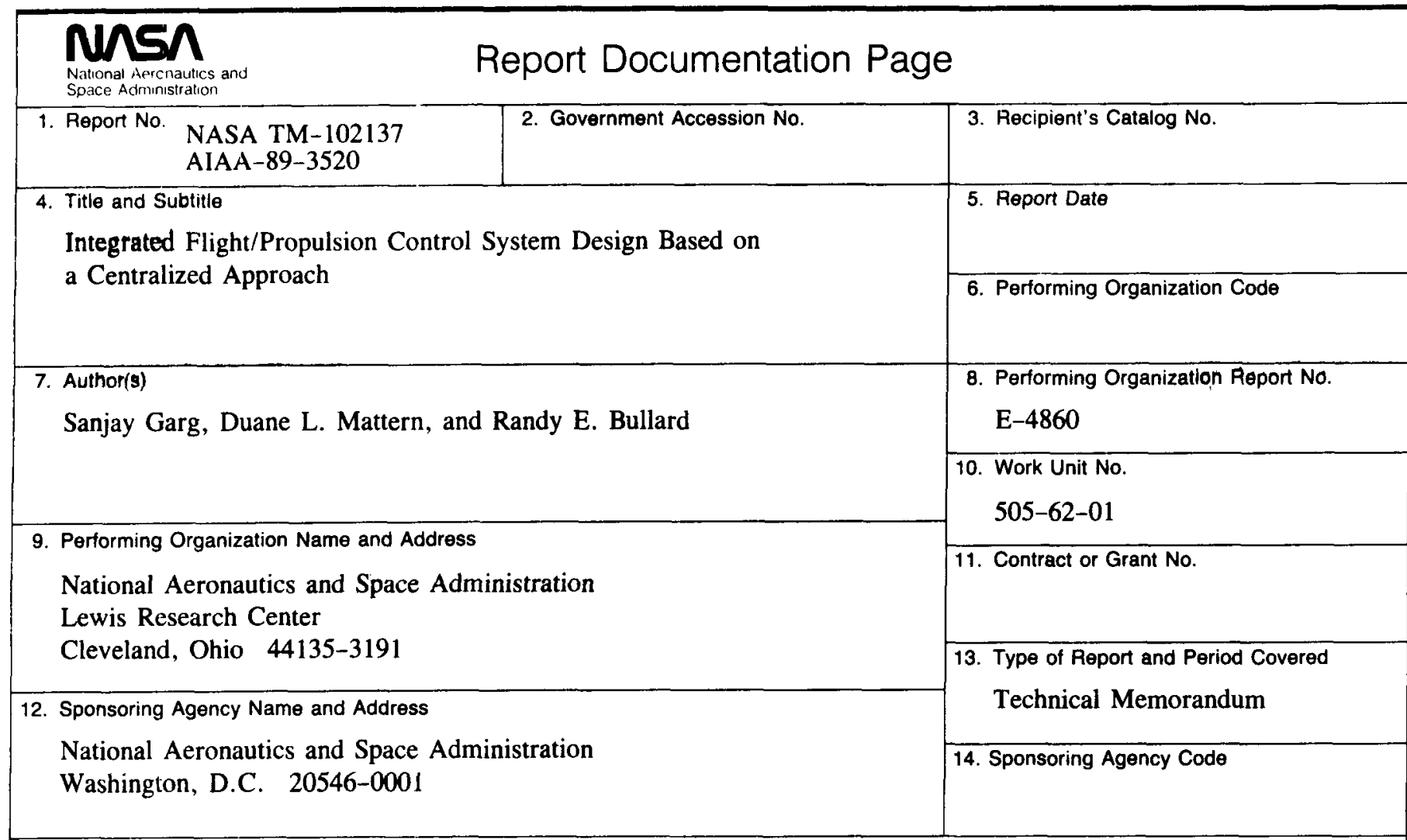

15. Supplementary Notes

Prepared for the Guidance, Navigation and Control Conference sponsored by the American Institute of Aeronautics and Astronautics, Boston, Massachusetts, August 14-16, 1989. Sanjay Garg and Duane L. Mattern, Sverdrup Technology, Inc., NASA Lewis Research Center Group, Cleveland, Ohio 44135. Randy E. Bullard, NASA Lewis Research Center; present address: M.K. Ferguson Co., Cleveland, Ohio.

16. Abstract

In this paper, an integrated flight/propulsion control system design is presented for the piloted longitudinal landing task with a modern, statically unstable, fighter aircraft. A centralized compensator based on the Linear Quadratic Gaussian/Loop Transfer Recovery methodology is first obtained to satisfy the feedback loop performance and robustness specifications. This high-order centralized compensator is then partitioned into airframe and engine "sub-controllers" based on modal controllability/observability for the compensator modes. The order of the sub-controllers is then reduced using internally-balanced realization techniques and the sub-controllers are simplified by neglecting the insignificant feedbacks. These sub-controllers have the advantage that they can be implemented as separate controllers on the airframe and the engine while still retaining the important performance and stability characteristics of the full-order centralized compensator. Command prefilters are then designed for the closed-loop system with the simplified sub-controllers to obtain the desired system response to airframe and engine command inputs, and the overall system performance evaluation results are presented.

17. Key Words (Suggested by Author(s))

Integrated Flight/Propulsion Control (IFPC); Linear Quadratic Gaussian (LQG); Loop Transfer Recovery (LTR); Compensator partitioning; Internally balanced realization; Prefilter
18. Distribution Statement

Unclassified - Unlimited

Subject Category 08

19. Security Classif. (of this report)

20. Security Classif. (of this page)

21. No of pages

40

22. Price*

Unclassified

Unclassified 